\title{
ENERGÍA: UN CAMBIO NECESARIO EN EL PERÚ
}

\author{
Pedro Gamio Aita \\ Plataforma Latinoamericana de \\ Energías Renovables (PLESE)
}

\section{Resumen:}

En este artículo se examina la situación que atraviesa el país en cuanto al excesivo uso de energías contaminantes (mayormente basadas en hidrocarburos), así como la problemática de un cambio gradual a energías más limpias y renovables que nos permitan hacer frente al cambio climático. Asimismo, se plantea la necesidad de políticas públicas para promover el desarrollo sostenible y sano del país, pues problemas de gobernabilidad y falta de institucionalidad dificultan su ejecución. Se analiza, además, el gran potencial de las energías renovables como la eólica y la geotermia, entre otras.

\section{Palabras clave:}

Hidrocarburos, Energías renovables, Contaminación ambiental, Cambio climático, Desarrollo sostenible, Políticas públicas, Medioambiente, Matriz Energética, Energía eólica, Geotermia, Energía termosolar. 


\title{
Energy: a necessary change in Peru
}

\begin{abstract}
:
In this article we examine the actual situation of our country regarding the excessive use of pollutant energy (mainly based in hydrocarbons), as well as the problematic of a gradual change to cleaner and renewable energy which will allow us to face the climate change. In addition, the need of public politics to promote the sustainable and healthy development of our country is posed, because governability problems and lack of institutionality may their execution difficult. We also analyze the great potential of renewable energies such as eolic and geothermal among others.
\end{abstract}

\section{Keywords:}

Hydrocarbons, Renewable energies, Environmental pollution, Climate change, Sustainable development, Public policies, Environment, Energy matrix, Wind energy, Geothermal energy, Solar thermal energy.

\section{Pedro Gamio Aita}

Abogado con Magister en gestión de políticas públicas por la Universidad Carlos III de España y egresado de la Maestría de Ciencia Política de la Pontificia Universidad Católica del Perú (PUCP). Postgrado en Gestión en ESAN. Con especialización en legislación ambiental por la Universidad Politécnica de Madrid, España y en Contratos de Energía por el Petroleum Institute of Texas.

Ha sido parte del equipo negociador del Perú en la COP20 y coordinador de Energía, participante en la COP21. Fue Viceministro de Energía del Perú desde agosto de 2006 hasta diciembre de 2008. Se ha desempeñado como consultor de la Fundación Adenauer, del Banco Mundial, del BID, PNUD, GIZ, WWF, OEFA y CEPLAN en materia de energía y medioambiente. También ha sido Director para América Latina de Global Village Energy Partnership, y asesor principal de dos fondos concursables, que han permitido la ejecución de 50 proyectos innovadores y replicables con tecnologías renovables en zonas rurales y de extrema pobreza.

Actualmente es Presidente del Panel Asesor de Monitoreo Independiente del Proyecto Camisea, por encargo del Eximbank, y Consultor de SNV, Servicio Holandés de Cooperación al Desarrollo. Asimismo, es integrante del Consejo Directivo de la Plataforma Latinoamericana de Energías Renovables (PLESE). 


\section{Introducción}

El país depende en un $72 \%$ de los hidrocarburos, lo que no guarda relación con el gran potencial de energías renovables. Asimismo, se nota una gran vulnerabilidad por la excesiva dependencia del gas natural y de un solo gasoducto. De otro lado, la creciente importación de petróleo y derivados eleva la contaminación ambiental; a esto hay que añadirle la concentración de la principal infraestructura, que favorece una economía centralizada. Además de ello, el controvertido privilegio de la calidad de los servicios energéticos se lo lleva la capital.

El sentido de este trabajo es analizar esta problemática, para plantear un cambio gradual en la matriz energética, ir hacia las energías limpias y lograr un crecimiento sustentable descentralizado. Está en juego la gobernabilidad y la capacidad de enfrentar el cambio climático: esta es la urgencia de una nueva política energética. Este esfuerzo deberá tener un planeamiento estratégico con metas de corto, mediano y largo plazo.

$\mathrm{Al}$ año 2015, la población del país alcanzó los 31 millones 151 mil 643 habitantes, de los cuales 15 millones 605 mil 814 son hombres y 15 millones 545 mil 829 son mujeres. Los cinco departamentos con más extensión territorial, Loreto, Ucayali, Madre de Dios, Puno y Cusco abarcan la mayor parte del territorio nacional, el 55\% de la superficie total del país. De estos, los tres más extensos se ubican en la selva; región en la que, por lo inhóspito de su territorio, hay una escasa concentración poblacional (INEI 2016).

Hoy nuestro país es un país de ingreso medio, por la actividad económica, principalmente en la $\operatorname{costa}^{1}$, la que representa un importante crecimiento económico a partir de la explotación de recursos naturales renovables y no renovables como la pesca, la minería polimetálica y los hidrocarburos. Junto con la gran riqueza en recursos minerales, se destacan los abundantes recursos energéticos renovables como son los

1 Los minerales se encuentran básicamente en la sierra y el gas en la selva, sin embargo, los beneficios se concentran en la costa, donde habita la mayor parte de la población. 
hídricos, aunque de heterogénea distribución. Asimismo, otra característica es la gran biodiversidad del país, que lo ubica entre los principales países megadiversos del mundo (CEPAL 2016).

En el Perú no solo se trata de debatir qué tipo de energía se usa o cuál es más económica y eficiente, también hay grandes carencias: casi tres millones de personas no tienen acceso moderno a la energía (INEI 2007) ${ }^{2}$. Esto agudiza la condición de pobreza y riesgo de enfermedad, sobre todo de las poblaciones aisladas rurales, puesto que viven grandes carencias en cuanto a la calidad del agua, la cocción de alimentos, la limpieza personal y del hogar.

Qué diferente es saber de mínimas condiciones de calidad de vida o del desarrollo sustentable de cualquier actividad productiva, el poder leer de noche, tener cadena de frío para preservar alimentos, vacunas o medicamentos o una bomba de agua para un mejor aprovechamiento del vital recurso. Con el acceso sostenible a la energía se logra obtener oportunidades que no se tenían antes y un gradual proceso de construcción de capacidades y conocimientos que le permitan al ciudadano o ciudadana, a la familia rural, entre otros, crecer, desarrollarse y ganar calidad de vida, dignidad y libertad. La falta de energía, ahonda más la pobreza y cierra la posibilidad de mejora para cualquier población.

La energía es como cualquier otro bien económico. Necesita de una administración decente, instituciones que funcionen y mercados eficientes, para que los electrones puedan ser llevados del productor al consumidor en bases sostenibles. Sin una fuente de energía confiable, prácticamente cualquier aspecto de la vida es afectado de forma negativa. A fin de cuentas, la energía es, en lo mínimo, la capacidad para realizar trabajos (Friedman 2010: 251).

Si hoy existe un concepto de democracia, este tiene que ver con poder ejercer derechos básicos, como el derecho a la salud, la alimentación, la energía y el derecho a un ambiente sano, lo que permite superar una economía de precaria subsistencia; es decir, lograr la infraestructura mínima para lograr desarrollo humano y producir excedentes. El rol del Estado es crucial para elaborar una estrategia ${ }^{3}$ que permita cambiar la matriz energética y generar oportunidades con una política energética que garantice los servicios básicos de acceso y adecuado uso de la energía, tanto para los hogares como para fines productivos. Como señala Friedman:

Dato del último censo a la fecha de la edición de este artículo.

3 Estrategia que puede ser concertada con la sociedad civil, la academia y la empresa privada, para involucrar a todos en la retadora tarea. 
Hoy, más que nunca, el crecimiento económico llega junto con el interruptor. La energía, hoy en día, libera mucho más conocimiento, estimula mucho más potencial, proporciona mucha más protección $\mathrm{y}$, como consecuencia, crea mucha más estabilidad que antes. Por lo tanto, la pobreza energética no solo mantiene a las personas más vulnerables envueltas en el atraso, sino que también nos priva a todos de sus contribuciones (2010: 253).

A esto le debemos sumar el contexto en el que vivimos. Una línea de base crítica señala que en la vida diaria se encuentran evidencias - a lo largo y ancho del territorio- de una controvertida situación ambiental, que agudiza la situación de los 7,8 millones de peruanos y peruanas en condición de pobreza, indicador basado en nivel de ingreso ${ }^{4}$. Son, entonces, precisamente los pobres los más afectados por la contaminación y falta de energía limpia, los ciudadanos que no tienen un adecuado servicio público de electricidad o agua, y solo acceden a una forma de transporte caótica ${ }^{5}$.

Hay un fuerte vínculo entre la contaminación y la energía: la basura que hoy contamina puede ser una fuente de generación de energía y de abono orgánico, pero arrojada en cualquier parte significa daño serio a la salud. A esto se suman los efectos del cambio climático, que es también una forma mayor de contaminación creada por la actividad humana a nivel global, con el abuso del uso de los recursos energéticos de origen fósil. Según Klaus Bosselmann,

Sin embargo, para la garantía de su seguridad energética, los Estados no deben estar focalizados sobre cualquier tipo de energía para satisfacer sus políticas de desarrollo, sino que deben estar amparados por la sostenibilidad del uso adecuado de energías renovables no convencionales, pues la utilización de las energías fósiles, tales como el petróleo, carbón, gas natural y gas licuado del petróleo y todos sus derivados, continuarán contribuyendo con una mayor contaminación ambiental, ampliando aún más las externalidades negativas del calentamiento global (2015: 25) ${ }^{6}$.

\footnotetext{
4 Sin embargo, si se mide por sus privaciones o muy limitado acceso a servicios, según un Estudio de la Universidad del Pacífico, utilizando una metodología desarrollada en la Universidad de Harvard, el 39,9\% todavía es pobre; es decir, 11,9 millones de peruanos.

5 El caos del transporte genera diez muertos por día en nuestro país.

6 Bosselmann señala también que, «La sostenibilidad es al mismo tempo simple y compleja. Semejante a la idea de justicia. La mayoría de nosotros sabe intuitivamente cuando alguna cosa no es 'justa'. De la misma manera, la mayoría de nosotros tiene plena consciencia de las cosas insostenibles: basura, combustibles fósiles, automóviles contaminantes, alimentos no saludables y así en frente. Podemos presumir también que muchas personas tienen
} 
El Perú enfrenta un gran desafío. Una sociedad que busca su desarrollo debe manejar con sumo cuidado y prudencia los recursos naturales renovables y no renovables a su alcance, así como el factor humano y los aspectos culturales y sociales vinculados con el manejo de los recursos; este último es el caso de la presencia de pueblos originarios que forman parte relevante de muchos espacios territoriales, precisamente donde subyacen los recursos energéticos no renovables. Por ello resulta un imperativo plantearse la interrogante de cómo lograr el desarrollo humano inclusivo y descentralizado desde un mejor uso de los recursos, y cómo la energía limpia bien aprovechada nos puede permitir alcanzar gradualmente mejores indicadores de desarrollo humano, respetando la cosmovisión de los diversos pueblos.

Un primer paso en este cometido es el planeamiento estratégico en la formulación de políticas públicas para promover el crecimiento sustentable de las actividades económicas. En el Perú falta articular políticas públicas sociales y económicas a favor de un ambiente sano y un desarrollo sustentable. Dentro de esta evaluación, los temas de energía y el uso de tecnologías renovables resultan esenciales por su importancia en la gestión del desarrollo.

El país enfrenta problemas de gobernabilidad, que guardan relación con las grandes brechas sociales y la precaria presencia del Estado en el territorio nacional, la deficiente capacidad de gestión y la falta de institucionalidad. Estos factores limitan la posibilidad de brindar adecuados servicios básicos y lograr una mejor respuesta, frente a la lucha contra la pobreza. El deterioro ambiental, las malas prácticas y la suma de pasivos ambientales, compromete a la fecha el 3,9\% del Producto Bruto Interno (PBI) (Banco Mundial 2007)7. Esto se resume principalmente en la contaminación del agua de los pozos, ríos y mar, la contaminación del aire en exteriores e interiores, la degradación de suelos, la deforestación, la desertificación, la acumulación de residuos sólidos donde vive la gente.

A los aspectos ambientales netamente locales, se le suman los efectos del cambio climático, los cuales se proyectan en $4 \%$ de pérdida del PBI a 2025 (CAN 2008. Por ello, la vulnerabilidad de nuestro país frente al cambio climático y que lo coloca entre los países más expuestos en el mundo, es un aspecto relevante que no se puede ignorar. Los glaciares han retrocedido un $40 \%$ en los últimos treinta años, afectando nuestra disponibilidad de

una noción clara de justicia y sostenibilidad. Por ejemplo, sienten que un mundo justo y sostenible es bastante necesario, no importa que tan distante de un ideal puede estar» (2015: 25).

7 El estudio del Banco Mundial estimó que el costo económico de la degradación ambiental, reducción de los recursos naturales, desastres naturales, servicios ambientales inadecuados (tales como sanidad inadecuada) sumaban 8,2 billones de soles, equivalentes al 3,9 por ciento del PBI interno en 2003. 
agua a futuro, sobre todo en la costa, donde vive casi el $70 \%$ de peruanos. Asimismo, los modelos de escenarios climáticos indican que el Fenómeno del Niño, que se presentaba en promedio cada cincuenta años, podrá ser más intenso y más frecuente; ya ahora es más concurrente. De otro lado, se ha percibido un aumento en la recurrencia de sequías y heladas en cuencas de gran importancia por ser proveedoras de alimentos del país ${ }^{8}$.

En el Perú, de acuerdo con las cifras del Balance Nacional de Energía, se liberan alrededor de 2.550 ton/hora de CO2 debido al consumo de energía de combustibles fósiles (Referencia). Es importante por ello reducir vulnerabilidades, como la fuerte dependencia del petróleo, con una creciente dependencia de la importación; pero, ¿cómo reducir el consumo de petróleo por ser oneroso y contaminante? Aquí es donde surge la imperiosa necesidad de contar con una política pública en materia de energías limpias y eficiencia energética que permita diversificar y cambiar la matriz energética desarrollando capacidades propias, ganando competitividad y productividad, aprovechando el potencial nacional existente de energías renovables, reduciendo la huella de carbono y descentralizando la capacidad de generación con generación distribuida.

En el país, no obstante la importante penetración del gas natural, todavía tenemos una fuerte dependencia del petróleo. Esto no guarda coherencia con nuestro potencial de energías renovables, ni con las oportunidades de una mayor eficiencia energética y un mejor uso del gas natural; resulta una contradicción, una muestra de ineficiencia y falta de gerencia-país, no solo desde la perspectiva del cambio climático, la estrategia nacional de mitigación y la sostenibilidad del modelo, sino también de la propia competitividad del país.

La energía renovable más económica en nuestro país es todavía la generación eólica, seguida por la energía solar, que en los últimos meses ha batido récord de precios bajos en el mundo y seguro lo hará también en el Perú; en tercer lugar, está la hidroenergía. El potencial técnico eólico es de alrededor tres veces la potencia instalada actual, siendo sus costos de generación competitivos con la generación térmica, incluido el gas natural.

\footnotetext{
8 La base de datos de inventarios de desastres DESINVENTAR, tomada de registros periodísticos del período 1970-2011, permite realizar un análisis del tipo de desastre, su periodicidad, territorialidad y nivel de impacto. Se identifica así la concentración de desastres vinculados con el clima y eventos concatenados, en períodos considerados notables: i) los que se relacionan con el Fenómeno El Niño (FEN), que presenta períodos pico - 1970-1973, 1981-1984, 1993-1994, 1997-1998, 2001-2004- que coinciden especialmente con una mayor precipitación; ii) los que no presentan una correspondencia precisa con el FEN y muestran picos en otros momentos del período: el año 1990 para el caso de sequías, 1991 y 1995 para epidemias, y 2003-2004 para heladas. En suma, la ocurrencia de desastres desencadenados por fenómenos climatológicos no está únicamente vinculada al FEN.
} 
Otra fuente que se aprecia muy competitiva es la energía solar, la cual en Perú tiene un potencial aprovechable de tres a cuatro veces la cantidad de toda la potencia instalada actual. Además, tenemos tecnologías que funcionan las 24 horas del día: la geotermia, la energía termosolar y la biomasa, donde existe gran potencial muy poco aprovechado; aunque tienen un costo mayor, pero menor que utilizar la energía térmica a diésel.

En el Perú se dio un gran avance con la aprobación del Decreto Legislativo 1002 en mayo de 2008, el marco promotor de las energías renovables no convencionales más completo de la región. Al decir de la Agencia Internacional de Energía Renovable (IRENA, por sus siglas en inglés), «En América Latina se han identificado diseños de políticas innovadoras, en particular los que combinan las subastas con otros mecanismos de regulación» (IRENA 2015: 8). El problema hoy es que estamos avanzando muy lentamente; otros países de la región nos han superado, sin tener necesariamente un marco tan promotor. Según sostiene la Agencia Internacional de Energía (AIE), en 2050 la energía más importante será la energía solar. Se necesita decisión política y mejor gerencia-país, visión de lo que cuesta o costará no tomar determinadas decisiones. El Perú puede lograr una matriz desconcentrada, más diversa y competitiva, y con menor huella de carbono. Hagamos el cambio, busquemos la resiliencia. Las siguientes generaciones lo esperan de nosotros.

Antes de analizar el marco regulatorio vamos a identificar el potencial de energías renovables y cómo se viene aprovechando.

\section{Potencial de energías renovables}

\subsection{Hidroelectricidad}

El agua es hoy la principal energía renovable del Perú, habiéndose desarrollado 56 centrales hidroeléctricas que han significado un importante ahorro de recursos y una menor contaminación para el país. Además, dentro de los varios tipos de centrales el que se ha usado más es el de central de pasada, una tecnología aceptada por ser amigable con el cuidado del medioambiente, aunque siempre se requiere la evaluación ambiental del caso específico.

En el Perú, para el desarrollo dela actividad de generación hidroeléctrica, el Ministerio de Energía y Minas (MEM) otorga el derecho de concesión. Conforme el Decreto Ley № 25844, Ley de Concesiones Eléctricas (LCE), el MEM otorga concesiones temporales para el desarrollo de estudios hasta nivel de factibilidad y concesiones definitivas para la ejecución del proyecto hidroeléctrico. La concesión temporal no tiene carácter de exclusividad, mientras que la concesión definitiva sí es exclusiva y sin plazo determinado. 
El país cuenta con un potencial de casi 70.000 MW aprovechables, de los cuales utiliza un porcentaje menor. Se ha avanzado con la dación de los decretos ley $\mathrm{N}^{\circ} 1002$ y 1041, que han permitido la promoción de nuevos proyectos, tanto de pequeñas hidroeléctricas como de mediano tamaño, casi todas centrales de pasada que no conllevan represamiento mayor, lo que las hace amigables con el medioambiente, como se ha señalado líneas arriba. Se trata de licitaciones especiales de largo plazo, de hasta veinte años de contratación. Los proyectos hidroeléctricos ganadores podrán acreditar su poder de mitigación de gases de efecto invernadero (GEI), al evitar consumir diésel en la forma de generación térmica. En el caso de centrales con algún nivel de represamiento, que no califican para el mecanismo de desarrollo limpio (MDL en adelante) se recomienda evaluar escrupulosamente cada caso, el costo-beneficio y viabilidad ambiental y social, cuidar el tamaño del espejo de agua buscando reducir y mitigar sus consecuencias sobre el ecosistema, la biodiversidad, flora y fauna, en especial si se ubican en la Amazonía u otras zonas vulnerables. Al mismo tiempo, resulta importante valorar el reciente desarrollo de un gran número de pequeñas centrales hidroeléctricas al amparo del Decreto Legislativo № 1002 y el potencial desarrollo de microcentrales en zonas rurales con sistemas aislados. Es importante valorar la mayor seguridad energética de desconcentrar y diversificar las fuentes de generación, reduciendo el consumo de petróleo en la generación eléctrica.

\subsubsection{Barreras y avances}

A pesar del alto potencial hidroeléctrico que tiene el Perú, en los últimos años el crecimiento de la oferta de potencia efectiva de generación en centrales hidroeléctricas ha sido reducido en comparación con las centrales termoeléctricas a gas natural y diésel. Siguiendo el análisis FODA, se puede señalar que las principales barreras para el desarrollo de proyectos hidroeléctricos, en comparación con otras tecnologías como las centrales térmicas a gas natural, son las siguientes:

a) Montos de Inversión: Las centrales hidroeléctricas se caracterizan por tener bajos costos de producción (etapa de operación), pero muy altos costos de inversión (etapa de construcción), en comparación con otros tipos de tecnologías. Por cada MW de potencia instalada, se requiere una inversión estimada entre 1,5 a 2,5 millones US\$; y para una termoeléctrica a gas natural en ciclo simple, por ejemplo, se requiere un monto promedio estimado de inversión de 0,6 millones US\$ por cada MW instalados, que incluso se facilita bajo la modalidad de leasing. 
b) Períodos de Construcción: Ciertamente, las centrales hidroeléctricas de mediano tamaño tienen un período de construcción que en promedio es de cuatro a cinco años, mientras que una termoeléctrica a gas natural tiene un período de construcción de uno a un año y medio, aproximadamente. Estos mayores plazos implican mayores gastos financieros durante la etapa de construcción de una central hidroeléctrica, que tendría ingresos recién al sexto año mientras que la termoeléctrica los tendría antes del segundo año.

c) Financiamiento: La principal dificultad para lograr el financiamiento es el no contar con un contrato a largo plazo por la venta de la energía a un precio fijo, de tal manera que tenga garantizado un flujo de capital que asegure el retorno de la inversión. Esto ha sido corregido con el mecanismo de subasta especial de largo plazo, que más adelante explicaremos. La falta de oferta suficiente al año 2006 y la conjunción de este aspecto con los dos anteriores, en definitiva, determinó que en el Perú la inversión privada se oriente a la construcción de centrales térmicas a gas natural en lugar de centrales hidroeléctricas. Una central térmica requiere de menores montos de inversión y por su menor período de construcción genera ingresos cuatro años antes que en el caso de una hidroeléctrica.

d) Tarifas en Barra y Precio del Gas Natural: Desde el año 2001 hasta diciembre del 2004 las tarifas en barra, sobre la base de las cuales los generadores podían contratar la venta de su energía a los distribuidores para el mercado regulado, han sido fijadas considerando el precio promocional del gas natural de Camisea para los generadores eléctricos, determinándose así tarifas ciertamente bajas, que no eran suficientes para incentivar la inversión en centrales hidroeléctricas. Vale recordar que la primera central termoeléctrica a gas natural de Camisea, la de Ventanilla, empezó a operar en agosto de 2004. Es así que el precio del gas natural indirectamente también ha sido una variable que ha venido limitando el desarrollo de centrales hidroeléctricas. Además, en 1998 el Ministerio de Energía y Minas suspendió el otorgamiento de concesiones para nuevos proyectos hidroenergéticos.

Resulta necesario precisar que el precio barato o subsidiado del gas natural proveniente de Camisea o del Lote 88 es un caso único y particular. Se trata de yacimientos ya descubiertos por la Shell, que devolvió el lote, por lo que los costos de inversión en exploración para el productor fueron de cero. Además, se trata de yacimientos con alta composición de condensados, por lo que el principal negocio son los líquidos extraídos, así que cerca del 80\% de los ingresos del productor corresponden a la venta de los líquidos, lo que le ha permitido al operador recuperar sus inversiones. 
Para superar la ventaja de las centrales térmicas con un precio bajo del gas se expidió el Decreto Legislativo $N^{\circ} 1041$, que estableció la no remuneración de la potencia, que es más o menos el $25 \%$ de la tarifa eléctrica, por uso ineficiente del gas en ciclo simple. Lamentablemente esta norma fue suspendida indefinidamente por el Decreto de Urgencia Nº32-2010 quepromovióel exministro PedroSánchez, una controvertida norma cuya constitucionalidad puede ser puesta a discusión.

Desde hace ya un buen tiempo se ha sugerido, para neutralizar el efecto perverso de un gas barato en el sector eléctrico, un cargo al consumo ineficiente de dicho combustible para su uso en generación eléctrica en ciclo simple ${ }^{9}$, cuyos fondos pueden ser destinados a financiar nuevos estudios hasta nivel de prefactibilidad, proyectos hidroeléctricos de hasta $20 \mathrm{MW}$ y proyectos de alternativas renovables. El fin de esto es lograr que el Estado desarrolle y mantenga una cartera de proyectos licitables y reducir así el riesgo del inversionista, reforzando su rol promotor de la inversión.

e) Incentivos Tributarios: Adicionalmente, se han dictado leyes que otorgan beneficios tributarios a la inversión en energías renovables, como son:

i. $\quad$ Ley $\mathrm{N}^{\circ} 28876$, que dispone que la generación de energía eléctrica con recursos hidráulicos y otros renovables, puede acogerse al Régimen de Recuperación Anticipada del Impuesto General a las Ventas (IGV).

ii. Decreto Ley № 1058, que dispone el beneficio de la depreciación acelerada de activos, de hasta $20 \%$ cada año, para efectos del pago del impuesto a la renta, para las inversiones en hidroeléctricas y demás energías renovables.

En julio de 2006 se dio la Ley № 28832, Ley para Asegurar el Desarrollo Eficiente de la Generación Eléctrica, un importante cambio que mejora y complementa el marco legal del sector eléctrico, y en 2008 se aprobó el Decreto Legislativo $\mathrm{N}^{\circ} 1002$, ya mencionado. Conforme al marco legal del sector eléctrico peruano, todo generador puede comercializar su producción de energía bajo cinco modalidades:

a) Contratos con distribuidores, a través de las licitaciones de suministro de electricidad para el mercado regulado y/o libre del distribuidor. El precio tiene carácter de firme y es el correspondiente a la oferta de cada generador. No se distingue el tipo de tecnología. 
b) Contratos con distribuidores para su mercado regulado. El precio corresponde a la tarifa en barra que fija el Organismo Supervisor de la Inversión en Energía y Minería (OSINERGMIN).

c) Contrato con usuarios libres a precio negociado.

d) Transferencias en el mercado de corto plazo administradas por el Comité de Operación Económica del Sistema (COES). El precio corresponde al spot o costo marginal de corto plazo mecanismo con el cual se repaga la energía tomada de la red y no generada, para cubrir por el generador los contratos de sus clientes contratados.

e) Licitación de Recursos Energéticos Renovables (RER) a cargo de OSINERGMIN.

De estas modalidades, la tendencia es que la segunda se reduzca sustancialmente hasta casi desaparecer, lo que se ha logrado, y que la atención de la totalidad de la demanda del mercado regulado sea abastecida a través de las licitaciones de suministro de electricidad, de largo plazo. La modalidad licitaciones de suministro de electricidad es la más adecuada para lograr viabilizar la inversión en una central de generación debido a los contratos de suministro de largo plazo (de hasta veinte años) que se pueden obtener y que facilitarán la obtención del financiamiento correspondiente.

La Ley $\mathrm{N}^{\circ} 28832$ crea el mecanismo de licitaciones de suministro de electricidad convocadas por los distribuidores con el objetivo de reducir la intervención administrativa en la determinación de precios de generación mediante soluciones de mercado, y promover una efectiva competencia y nuevas inversiones en generación. El inconveniente sería que no distingue el tipo de tecnología o fuente de energía, de tal manera que puede ganar la licitación la opción más económica aunque no sea la opción más sostenible.

En cada licitación, las bases son propuestas por los distribuidores y aprobadas por OSINERGMIN, quien también fija un precio tope escondido de adjudicación para dicha licitación. El precio de venta de energía a los distribuidores es el ofertado por cada postor y el precio de potencia corresponde al precio básico de potencia - que fija OSINERGMIN-vigente a la fecha de la convocatoria de la licitación. Ambos precios tienen carácter de firmes durante el período contractual (hasta por 20 años) y se actualizan durante la vigencia del contrato aplicando las correspondientes fórmulas de actualización establecidas en las propias bases de la licitación.

La mencionada Ley № 28832 establece que en las licitaciones se aplica un factor de descuento a las ofertas económicas respaldadas con proyectos hidroeléctricos para efectos de su evaluación, toda vez que esos proyectos implican mayores costos de inversión que los proyectos térmicos. La aplicación de dichos factores de descuento es únicamente para efectos de la evaluación de la oferta económica, pues todo postor que se convierta en 
adjudicatario siempre recibirá por la venta de su energía el precio que haya ofertado en la licitación. Esto fue modificado por el Decreto Legislativo $\mathrm{N}^{\circ} 1002$, Ley promotora de las energías renovables, así como también la decisión de hacer concursos de hidroeléctricas a cargo de PROINVERSIÓN.

Posteriormente a la Ley $\mathrm{N}^{\circ} 28832$ el Estado define realizar estas licitaciones conforme a las necesidades del mercado, pero ya no dejar competir a todas las tecnologías juntas, sino más bien definir un concurso por tecnología específica, como la hidroelectricidad y así favorecer el desarrollo de las energías renovables.

\subsection{Energía Eólica}

Con la publicación del mapa eólico en $2008^{10}$ se ha mostrado el gran potencial eólico que tiene el país - fundamentalmente en la costa-, con 22.500 MW de potencia aprovechable (Ministerio de Energía y Minas et al. 2008). Las subastas especiales para las energías alternativas, como la eólica, califican para el mecanismo de desarrollo limpio (MDL); un MDL programático ${ }^{11}$ que el Perú puede desarrollar ayudando en la gestión y desarrollo de los parques eólicos.

Las cuatro subastas de energías alternativas han sido un gran paso, en el que se ha evidenciado que muchas críticas y objeciones se basan en el desconocimiento de las nuevas tecnologías o en lobbies y resistencias previsibles de grupos de interés. Lo cierto es que los cambios del reglamento hasta en tres oportunidades y el retraso en el calendario de ejecución no favorecen el desarrollo de las alternativas renovables o no convencionales; pero se puede corregir la falta de continuidad y estabilidad en las políticas en curso. Una primera y urgente medida es la convocatoria a más subastas, sin discriminar la energía eólica o solar, que completen el mandato de cubrir el 5\% - que se debió lograr el año 2013 - y luego se incremente, como participación del total de la energía que se comercializa en el país.

El mayor potencial eólico en el Perú se ubica a lo largo del litoral, donde es frecuente encontrar zonas que registren velocidades de viento mayores a $5 \mathrm{~m} / \mathrm{s}$, es decir la velocidad mínima para considerar económicamente factible la generación eléctrica a partir de este recurso (Velásquez 2007). Esto se debe a la fuerte influencia del anticiclón del Pacífico y de la Cordillera de los Andes, que generan vientos provenientes del suroeste en toda la región de la costa. De acuerdo al mapa eólico la potencia eólica aprovechable del Perú se

\footnotetext{
${ }^{10}$ El mapa eólico fue concretado por el Ministerio de Energía y Minas por medio del proyecto FONER con el Banco Mundial.

11 MDL programático es la suma de varios proyectos empaquetados, para hacer un volumen mayor de Gases de efecto invernadero que se evitan emitir. Favorece la negociación de bonos de carbono.
} 
estima en algo más de $22.500 \mathrm{MW}$, como ha sido señalado líneas arriba, sin considerar zonas en el mar. Las zonas de mayor potencial se ubican desde Ica hasta Tacna por el sur y desde Ancash hasta Tumbes por el norte. De modo más específico resaltan: Yasila, Paita y Talara (en Piura); Chiclayo (en Lambayeque); Malabrigo y Trujillo (en La Libertad); Chimbote y Pacasmayo (en Ancash); San Juan de Marcona, Laguna Grande y Paracas (en Ica); Punta Ático (en Arequipa); y El Ayro y Punta de Coles (en Moquegua) (CENERGIA 2004).

Las primeras mediciones del potencial eólico con fines energéticos fueron realizadas por la Empresa Electricidad del Perú (Electroperú), la Corporación Peruana de Aeropuertos y Aviación Comercial (CORPAC) para navegación aérea y el Servicio Nacional de Meteorología e Hidrología del Perú (SENAMHI). Esta última es la entidad oficial encargada de evaluar los registros de vientos a nivel nacional y actualmente cuenta con un banco de datos de viento a escala nacional, lo que le permite realizar estudios de energía eólica en algunos puntos del país a través de su Dirección General de Investigación y Asuntos Ambientales.

\section{Principales trabajos de la Dirección General de Investigación y Asuntos Ambientales del SENHAMI orientados a evaluar el potencial eólico a nivel nacional}

- Atlas Eólico Preliminar de América Latina y el Caribe: Perú y Bolivia (Vol. IV): preparado por OLADE en 1983. Se basó en mediciones realizadas en 48 estaciones distribuidas por todo el país.

- Mapa de zonas con mejores posibilidades de explotación de aguas subterráneas mediante el uso de aerobombas: elaborado por el AFATER/INAF en la década de 1980.

- Mapa Eólico (incluido en el Estudio Nacional de Evaluación de aerobombas): preparado por ITINTEC para el Banco Mundial en 1987.

- Atlas Eólico Preliminar: preparado por Electro Perú en la década de 1990.

- Mapa de Potencial Disponible de Energía Eólica (incluido en el Atlas Minería y Energía en el Perú): editado por el MEM desde el año 1995. Se basa en valores de velocidad de viento de 32 estaciones de medición.

- Mapa Eólico Preliminar (incluido en el documento interno Informe del Potencial Eólico del Perú): preparado por la DEP en 1998.

- Mapa Eólico Preliminar del Perú: preparado por ADINELSA en el 2007. Se basa en registros de 153 puntos de Electro Perú y la cooperación italiana de ICU en el período 1985 - 1986; y datos de SENAMHI y CORPAC del período 1985 - 1993.

- Mapa Eólico del Perú: elaborado para el MEM a través del Consorcio Metosim Truewind S.L. y Latin Bridge Bussiness S.A. 


\section{Estudios de otras instituciones orientados a evaluar el potencial eólico a nivel nacional}

De manera más específica, diversas instituciones han realizado evaluaciones de vientos en varios lugares:

- $\quad$ Estudio meteorológico del departamento de Piura: ITINTEC en 1980.

- $\quad$ Estudio de vientos de Characato, Arequipa: ITINTEC en 1981.

- Estudio de vientos del departamento de Puno: consultora alemana ITC a solicitud del Convenio GTZ - CORPUNO entre 1982 y 1983.

- $\quad$ Estudio de vientos de Lurín y Villa en Lima: ITINTEC en 1984.

- Estudio de vientos en Apurímac y Junín: ITINTEC en 1984.

- Medición del viento en Yasila, Piura: Electro Perú en 1994.

- Medición del viento en San Juan de Marcona, Ica: Electro Perú en 1994, ADINELSA entre 1998 y 2005, y ABB - Alemania entre 2001 y 2002. (Se registraron velocidades promedios de $9 \mathrm{~m} / \mathrm{s}$ ).

- Medición de la velocidad del viento en Punta Malabrigo, La Libertad: PUCP en 1995 y ADINELSA entre 1996 y 2005. (Se registraron velocidades promedios de $8 \mathrm{~m} / \mathrm{s}$ ).

- Medición del viento en Pacasmayo, La Libertad: KLT Consult - Alemania entre 2002 y 2003. (Se registraron velocidades promedios de $6,9 \mathrm{~m} / \mathrm{s}$ ).

- Medición del viento en Paita, Piura: KLT Consult - Alemania entre 2002 y 2003. (Se registraron velocidades promedios de 7,8 m/s).

- Medición del potencial eólico de Los Perros, Piura: empresa ecuatoriana ProViento S.A. (Se registraron velocidades promedios de 7,4 m/s).

Fuente: CENERGIA, 2004; CER UNI, 2005b.

Según los mapas eólicos del Perú calculados a 50, 80 y 100 metros respectivamente, las zonas con mayor potencial para la generación eólica de gran capacidad están en la costa, específicamente en las regiones de Piura, Lambayeque e Ica, que registran mayores velocidades de viento promedio anual.

La energía eólica todavía es una tecnología de uso diurno, es decir no puede operar las 24 horas del día, pero por las características de nuestro potencial en la costa, funciona con gran estabilidad 12 horas y puede complementarse con la hidráulica u otras fuentes de generación. Es precisamente el período de estiaje el mejor momento de los vientos en la costa peruana, los mismos que tienen una vocación energética por su estabilidad y potencia. 


\subsection{Energía solar}

El sur del Perú, junto al norte de Chile, tiene un potencial extraordinario de energía solar. Es precisamente donde se ubica el desierto de Atacama, que hoy se puede aprovechar, al haberse alcanzado costos muy competitivos en la tecnología fotovoltaica ${ }^{12}$. Además de ello, en la sierra la energía solar sola o combinada con otras fuentes energéticas resulta una herramienta eficaz de acceso a la energía de muchos centros poblados aislados. No olvidemos que hay casi tres millones de peruanos sin energía eléctrica. Asimismo, en los departamentos de Arequipa, Moquegua y Tacna la radiación solar permite comenzar a trabajar aprovechamientos mayores, considerando el avance tecnológico y la reducción de costos, de la tecnología fotovoltaica.

Según el Atlas de Energía Solar del Perú (SENAMHI 2003) el país tiene un potencial extraordinario. La zona de mayor potencial de energía solar del país se encuentra en la costa sur, en las regiones de Arequipa, Moquegua y Tacna (entre los $16^{\circ}$ y $18^{\circ}$ de latitud sur), donde el promedio anual de energía solar incidente diaria está en un rango de 6,0 a 6,5 kW.h $/ \mathrm{m}^{2}$. Otras zonas con alta disponibilidad de energía solar diaria, entre 5,5 a $6,0 \mathrm{~kW} \cdot \mathrm{h} / \mathrm{m}^{2}$, se encuentran en la costa norte, en las regiones de Piura y Tumbes (entre los $3^{\circ}$ y $8^{\circ}$ de latitud sur), y en gran parte de la sierra, sobre los $2500 \mathrm{msnm}$.

La zona de menores valores de energía solar en el Perú es la selva, en las regiones de Loreto, Ucayali y Madre de Dios, donde se registran valores de 4,5 a $5,0 \mathrm{~kW} \cdot \mathrm{h} / \mathrm{m}^{2}$, con una zona de mínimos valores en el norte de la región Loreto (entre los $0^{\circ}$ y $2^{\circ}$ de latitud sur). No obstante, la alta dispersión de las poblaciones en estas zonas y su particular geografía (escasez de caídas hidráulicas y de recurso eólico) determinan que muchas veces la bioenergía o la energía solar fotovoltaica sea la opción más conveniente en la selva, a pesar de la menor disponibilidad. Según el mes del año y la ubicación geográfica, la energía solar diaria acumulada se encuentra en un rango de 2 a $8 \mathrm{~kW} \cdot \mathrm{h} / \mathrm{m}^{2}$. Sobre esta base se podría afirmar que la media nacional rondaría los $5 \mathrm{~kW} . \mathrm{h} / \mathrm{m}^{2}$. Esto es importante si se considera que, valores iguales o superiores a $4 \mathrm{~kW} . \mathrm{h} / \mathrm{m}^{2}$ hacen atractivo el uso de tecnologías de conversión fotovoltaica ${ }^{13}$. Por otra parte, una característica muy importante de la energía solar en el Perú es su constancia durante el año: los promedios mensuales no varían más del $20 \%$. (Horn 2007).

\footnotetext{
12 México, Emiratos Árabes Unidos y Marruecos han alcanzado precios menores a 30 dólares MW/hora

${ }^{13}$ Estudios elaborados por el Centro de Investigaciones en Energías Renovables de la UNI en 2005.
} 
Si aplicáramos adecuadamente la tecnología solar en campos como la salud o vivienda, con diseños bioclimáticos, no deberían morir personas por friaje. Las casas bioclimáticas asegurarían una temperatura diferente y mayor a la exterior, protegiendo personas, y los cobertizos bioclimáticos protegerían a los animales, único capital de las familias más pobres en la sierra andina. La energía no solo ilumina, sino también da calor, calienta el agua, preserva medicamentos y alimentos, y tecnifica las formas de producción.

Las energías eólica y solar fotovoltaica son conocidas como fuentes intermitentes, es decir que se no cuenta con ellas las 24 horas del día. No obstante esta limitación, el factor de planta o rendimiento es mucho mayor en el Perú que en regiones como Europa, por lo que su aprovechamiento es importante y mucho más rendidor. Según estudios técnicos contratados por el COES, el Perú puede aprovechar, con las actuales limitaciones, la energía intermitente hasta más o menos $1.500 \mathrm{MW}$, por las debilidades de nuestro sistema de transmisión y por el sistema de despacho donde no todo está automatizado. En la medida en que crezca la infraestructura, que tengamos nuevas líneas de transmisión bidireccionales, varios anillos energéticos configurados y un sistema de despacho de la energía automatizado, se podrá usar mucho más la energía eólica y la energía solar fotovoltaica. Se necesitan sistemas de transmisión más poderosos, líneas de $500 \mathrm{~kW}$ inteligentes que permitan responder a la intermitencia de algunas fuentes sin perjudicar la confiabilidad del sistema.

\subsection{Bioenergía}

Entre las medidas que puedan garantizar que la producción de bioenergía también diversifique la matriz, promueva nuevos emprendimientos y reduzca la pobreza y el hambre, está la generación distribuida ${ }^{14}$. Se trata de incluir, entre otros, el apoyo de regulaciones medioambientales para garantizar que el impacto de la producción de bioenergía en la tierra, la biodiversidad, el agua y los suelos, sea minimizado. En algunos casos ya existen modelos para mitigar los riesgos que conlleva la producción a gran escala de biomasa, especialmente a la producción asociada con materia prima para la producción de biocombustibles líquidos. Pero la bioenergía no se limita a este campo, también tiene que ver con el aprovechamiento energético de la basura orgánica y los residuos forestales; esto es especialmente importante en países con significativa vocación forestal como el Perú.

14 Falta solo reglamentar la aplicación de la generación distribuida. Es la capacidad de entregar energía al sistema por pequeños generadores, que son al mismo tiempo consumidores de energía, a partir de la instalación de sistemas con tecnologías renovables. 
La biomasa es una fuente de energía renovable llamada también bioenergía, que se obtiene a partir de residuos agrícolas, agroindustriales, forestales y urbanos. Su aprovechamiento como energía final se da de tres formas: como fuente de calor, como energía eléctrica, y como fuerza motriz para su uso en el transporte. La bioenergía puede obtenerse de forma gaseosa, sólida y líquida a través de los llamados biocombustibles e involucra una serie de materias primas, tecnologías, productos y equipamiento.

En general, puede decirse que el potencial de biomasa existente en el país para usos energéticos no está debidamente valorizado. Esto se debe a que no se han actualizado estudios que evalúen dicho potencial y a que incluso los existentes no evalúan la real disponibilidad del recurso bajo criterios de sostenibilidad, es decir considerando salvaguardar la seguridad alimentaria, evitando la deforestación y el empobrecimiento de la calidad de nutrientes del suelo, entre otros aspectos. Sin embargo, según el estudio desarrollado en 1988 por el Programa de las Naciones Unidas para el Desarrollo (PNUD) con respecto al Plan de Desarrollo de las Energías Renovables, el potencial teórico anual estimado de los recursos energéticos de la biomasa en el Perú es el siguiente:

- Forestal:

- Bosques de libre disponibilidad (36,8 millones de Ha): 767.580 GW.h/año.

- Residuos:

- Agrícolas: 8.048 GW.h/año.

- Pecuarios: 13.235 GW.h/año.

- Vacuno: 4.800 GW.h/año.

- Urbano (4 millones de personas): 2.908 GW.h/año.

- Agroindustriales:

- Bagazo de caña: 4.700 GW.h/año.

- Cáscara de arroz: 710 GW.h/año.

- Residuos de aserraderos: 372 GW.h/año.

La biomasa como fuente de energía tiene posibilidades de utilizarse en el sistema interconectado y en sistemas aislados. Existen tres grandes macrorregiones donde la biomasa presenta un interesante potencial para ser usada con fines energéticos de mediana y gran potencia ${ }^{15}$ : la costa norte (bagazo de caña, cascarilla de arroz, residuos hidrobiológicos), la selva alta (cascarilla de arroz y café, residuos forestales), y la selva baja

${ }^{15}$ La empresa Green Energy realizó un estudio sobre el tema en 2005. El documento no ha sido publicado. 
(residuos forestales). Respecto del consumo de leña, en la costa norte una gran proporción proviene de los bosques secos. En la región de la sierra, considerada por la Organización de las Naciones Unidas para la Alimentación y la Agricultura (FAO) como región en situación de escasez aguda de biomasa (Orrego 2011), los ecosistemas naturales usualmente utilizados como fuente de energía son los bosques de queñuales y otras formaciones boscosas como los totorales y los yaretales. En esta región las plantaciones de eucalipto han contribuido parcialmente en la solución del problema energético, lo que ha impulsado la realización de programas intensivos de reforestación con fines energéticos, es decir, la indispensable reposición de lo talado, pues de lo contrario esta actividad no sería sostenible. Finalmente, en la selva, la abundancia de biomasa permite afirmar que su consumo no tiene restricción, en tanto sea un manejo sostenible de los residuos.

El reto del país es sacar adelante plantaciones forestales en las áreas degradadas o deforestadas ${ }^{16}$, generando un gran potencial energético de la biomasa, que puede permitir al mismo tiempo un programa agresivo de reforestación.

Hoy tenemos las tecnologías modernas como las bio-refinerías que aprovechan la bioenergía y todos los tipos de desperdicios (agrícolas, industriales, mineros y domésticos). Los orgánicos se convierten en biocombustibles sólidos y producen electricidad con turbinas a vapor; con las llantas se produce diésel sintético que es mejor que biodiésel y el resto es aprovechado como materiales de construcción. Así se cumple con cinco criterios básicos: casi cero emisión de $\mathrm{CO} 2$, un factor de planta del $90 \%$, se genera donde está la demanda y por lo tanto hay menos pérdida de distribución, se resuelven problemas ambientales directos e indirectos (por ejemplo la contaminación del agua, suelo y aire) y al aprovecharse todos los desperdicios se reduce la contaminación y la demanda de espacio físico para disponerlos.

\subsection{Geotermia}

El Perú forma parte del Círculo de Fuego del Pacífico, zona caracterizada por la ocurrencia de movimientos sísmicos, fenómenos tectónicos y elevada concentración de flujo tectónico. Por ello hay en el país numerosas fuentes termales con temperaturas entre $40^{\circ}$ a $90^{\circ} \mathrm{C}$, ubicadas principalmente en la Cordillera Occidental de los Andes y en el Altiplano Sur. Según la Organización Latinoamericana de Energía (OLADE), el Perú tendría 156 zonas geotérmicas identificadas; además, se han reconocido más de 200 vertientes de agua

${ }^{16}$ Se estima en 12 millones de hectáreas las tierras degradadas. 
caliente, así como fumarolas y algunos geiseres con temperaturas cercanas a los $100^{\circ} \mathrm{C}$ (Gamio 2010).

El mayor potencial geotérmico del Perú se encuentra en seis regiones denominadas geotérmicas (Gamio 2010):

- Región I: Cajamarca (en el departamento del mismo nombre).

- Región II. Huaraz (en Áncash y La Libertad).

- Región III: Churín (en Lima, Pasco y Huánuco).

- Región IV: Central (en Huánuco, Huancavelica y Ayacucho).

- Región V: Cadena de conos volcánicos (en Ayacucho, Apurímac, Arequipa, Moquegua y Tacna).

- Región VI: Puno y Cusco (en los departamentos del mismo nombre).

Las principales áreas de interés serían (Aguinaga, 2006; Coviello, 2006):

- En la región V: Challapalca (en Tacna y Puno); Tutupaca (en Tacna y Moquegua); Calacoa (en Moquegua); Laguna Salinas - Chivay (en Arequipa). En Challapalca se habría registrado en 1988 un acuífero profundo con $270^{\circ} \mathrm{C}$.

- En las regiones I y II: Callejón (en Ancash); Otuzco y La Gramma (en La Libertad y Cajamarca); y Cajamarca (en Cajamarca).

Entre los principales estudios y evaluaciones realizadas se tienen (Aguinaga, 2006):

- En 1975, Minero Perú: exploración preliminar de manifestaciones geotermales de Calacoa y Salinas (Moquegua).

- En 1976, Geothermal Energy Research del Japón: exploraciones preliminares en la cuenca del Vilcanota (Cusco).

- En 1977, INIE: primer censo de manifestaciones geotermales.

- En 1978, INGEMMET: inventario y una agrupación geográfica de afloramientos geotermales (se definieron las Regiones Geotermales).

- Entre 1979 y 1980, INGEMMET y Aquater de Italia: estudios de reconocimiento geotérmico de Región $\mathrm{V}$ (identificando áreas de interés: Tutupaca, Calacoa, Challapalca, Salinas, Chachani y Chivay).

- En 1980, Geothermal Energy System Ltd.: estudios de reconocimiento geotérmico en las zonas de Calacoa, Tutupaca y Salinas (Moquegua).

- Entre 1983 y 1985, INGEMMET y British Geological Survey: inventario parcial de manifestaciones geotermales en Región VI (Cusco y Puno). 
- Entre 1983 y 1986, ELECTROPERÚ y Cesen de Italia: estudios de reconocimiento geotérmico en Regiones I a IV; y estudio de prefactibilidad en La Gramma (Cajamarca).

- En 1986, ELECTROPERÚ con asistencia técnica de IAEA y ONU: investigaciones geoquímicas en la Región V (Tacna y Moquegua).

- En 1997, CENERGÍA, con apoyo del IIE de México: evaluación de información y estudios disponibles (realizados por INGEMMET, ELECTROPERÚ, Proyecto Especial Tacna, IPEN y la Cooperación Internacional).

En el caso de la geotermia, aún es necesario hacer las primeras perforaciones para reducir el riesgo de 90 a 10\% en los proyectos existentes en el nivel de prefactibilidad; esto aseguraría tarifas más económicas en la etapa de aprovechamiento comercial del recurso. Sobre la base de los

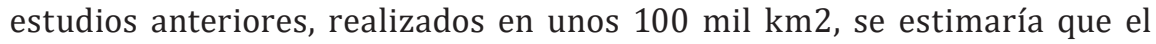
potencial geotérmico del Perú se encontraría en 2.990 MW (Gamio 2010). Finalmente, resulta importante el aporte del plan maestro de Geotermia, realizado por la Agencia de Cooperación Internacional de Japón (JICA, por sus siglas en inglés).

El país, gracias a la cooperación del Japón, ha avanzado con el estudio de prefactibilidad de dos proyectos sobre potencial geotérmico en el departamento de Tacna: Borateras y Corrientes. Además, se ha terminado el primer Plan Maestro de Geotermia, donde se identifica un potencial de $3.000 \mathrm{MW}$. Ya existen los aspectos básicos para avanzar en el aprovechamiento de esta fuente de energía renovable no convencional, presente en por lo menos seis departamentos del país.

\section{Medidas pendientes}

Es importante el avance con acciones concretas y voluntad política para incentivar la inversión en energías renovables alternativas. Sin embargo, aún hay medidas pendientes de adoptar para promover la diversificación de la matriz energética con el fin de coadyuvar hacia un abastecimiento seguro, oportuno y eficiente de la demanda de energía eléctrica. Entre estas se puede mencionar:

a) El planeamiento estratégico, como rol del Estado, que prevea en el largo plazo el nivel de participación eficiente de cada tecnología en la oferta de generación y sea concertado con la empresa privada, la academia y la sociedad civil. Con el fin de garantizar la implementación de dicho planeamiento, el Estado es quien aprueba la oportunidad en que se 
convoquen las licitaciones especiales de suministro de electricidad de largo plazo; asimismo, quien hace licitaciones por mayores demandas de energía promoviendo una mayor competencia, orientando las inversiones en nueva oferta de generación hacia un crecimiento descentralizado, distinguiendo por tecnologías y definiendo cuál va a ser priorizada sobre la base de un análisis costo-beneficio y una evaluación ambiental estratégica. Para ello, los distribuidores y las empresas comunican sus requerimientos futuros de energía.

b) El Perú presenta naturalmente una estructura de consumo y generación seccionada en no menos de tres grandes macrorregiones: norte, centro y sur. Hacia estas regiones debería dirigirse la solicitud o llamado a licitación para proveer de energía limpia; así, el efecto de localización descentralizada jugaría del lado correcto para mantener racionales y equilibrados los costos de generación y de la propia red de transmisión eléctrica nacional, en tanto y paralelamente se desarrolle la generación distribuida ${ }^{17}$.

c) Como medida complementaria a los puntos mencionados, falta cumplir y perfeccionar la Cuarta Disposición Complementaria Final de la Ley $\mathrm{N}^{\circ} 28832$, la cual dispone que el MEM debe poner a disposición de los futuros inversionistas un paquete de proyectos con estudios hasta el nivel de prefactibilidad. También se debe facilitar los correspondientes estudios de impacto ambiental con la finalidad de reducir los riesgos al inversionista y acortar los plazos de realización de muchos proyectos necesarios, y así el Estado tenga un rol más eficaz. Esto aceleraría la diversificación de la matriz energética.

d) Bajo el esquema de contratos de venta de energía hasta por veinte años a precios firmes actualizables y como resultado de licitaciones especiales de suministro de electricidad los proyectos serían viables y conseguirían financiamiento fácilmente, por lo que el tema del bajo precio del gas natural del Lote 88 para los generadores ya no sería una barrera insalvable, más aún si al año 2024 ya las reservas de este lote no serán suficientes para atender al mercado interno. Sin embargo, a pesar de no ser tema directo del presente artículo, la aplicación de un impuesto o cargo al consumo ineficiente de dicho combustible para su uso eléctrico se considera una posible medida necesaria y pendiente para promover de manera efectiva el uso eficiente en la generación eléctrica a través de la tecnología del ciclo combinado. Una medida para desalentar el consumo ineficiente del gas natural se dio con el Decreto Legislativo $N^{\circ} 1041$, que no remuneraba por potencia el uso 
del gas natural en ciclo simple — donde se desperdicia casi $80 \%$ del recurso-, pero inexplicablemente la norma fue suspendida por un Decreto de Urgencia en la gestión del ex Ministro Pedro Sánchez. En el Decreto Legislativo $\mathrm{N}^{\circ} 1041$ la remuneración por potencia, que es un componente de la tarifa, solo procede si hay un uso eficiente del gas natural.

Otro motivo de reflexión es aprender de nuestros errores como país. Uno de ellos fue el resultado poco satisfactorio de la primera licitación de largo plazo de hidroeléctricas que convocó PROINVERSION por la insistencia en mantener un precio tope que no corresponde al mercado y también la entonces evidente falta de proyectos con estudios suficientes; error que se corrigió con una nueva convocatoria, que consiguió un resultado positivo. Pero no se permitió la participación de asociaciones público privadas, discriminando a las empresas estatales que se habían asociado con empresas privadas. La consecuencia fue que hubo menos proyectos hidroeléctricos concursando que los esperados y ante la necesidad de suministro por una creciente demanda eléctrica, la mayor parte de la demanda se fue por el camino de las licitaciones generales de distribuidoras, donde no se distingue la tecnología. Así pues, las centrales térmicas tienen un costo inicial mucho menor, de tal manera que se terminó por comprometer el crecimiento eléctrico a un mayor consumo de hidrocarburos; esto aceleró el uso del gas natural, lo que no es sostenible en el largo plazo, por el carácter limitado de las reservas. Este error de 2009 se ha venido repitiendo y también se dio en 2013, acentuándose la mayor dependencia eléctrica a centrales térmicas a gas natural. Hoy tenemos en las centrales térmicas casi el $50 \%$ de la oferta eléctrica nacional. Lo recomendable era no exceder un tercio.

Una buena señal han sido las cuatro primeras subastas de energías alternativas que no obstante su retraso, han marcado un hito. En 2009 se llevó a cabo la primera subasta de suministro de electricidad con RER, en el marco del Decreto Legislativo $\mathrm{N}^{\circ}$ 1002, Ley de promoción de la inversión para la generación de electricidad con el uso de energías renovables. Conforme al referido marco legal, el MEM elaboró las bases de la subasta, encargándose a OSINERGMIN la conducción del proceso. Dicho proceso se inició el 21 de agosto de 2009 con la publicación del Aviso Previo por parte del MEM y la apertura del Registro de Participantes en el Portal Web de OSINERGMIN, quien efectuó la correspondiente convocatoria, el 15 de octubre de 2009. La presentación de sobres técnicos y económicos se efectuó el 18 de enero del 2010, publicándose la relación de postores calificados el 29 de enero del 2010. El 12 de febrero del 2010 se llevó a cabo el acto público de apertura de sobres económicos y otorgamiento de la buena pro de la primera Subasta RER. A esta 
etapa calificaron 20 postores con 31 proyectos; 17 proyectos hidroeléctricos, 6 eólicos, 2 de biomasa, y 6 solares; finalmente, los proyectos adjudicados fueron 26. Los precios máximos de adjudicación fijados por OSINERGMIN para las tecnologías hidroeléctrica, eólica, biomasa, y solar fueron de 74 US\$/MWh, 110 US\$/MWh, 120 US\$/MWh, y 269 US\$/MWh, respectivamente. Estos precios fueron mantenidos en reserva por el notario público, y dados a conocer al inicio del acto público de apertura de sobres económicos y otorgamiento de la buena pro. La media de los precios adjudicados (ofertados por los postores adjudicatarios) fueron como sigue:

Cuadro 1

Media de precios adjudicados en la primera subasta de suministro de electricidad con RER (2010) (en US\$/MWh)

\begin{tabular}{|l|c|c|c|}
\hline \multicolumn{1}{|c|}{ Tecnologías } & Media & Mínimos & Máximos \\
\hline Hidro & 60,20 & 55,00 & 70,00 \\
\hline Eólica & 80,36 & 65,50 & 87,00 \\
\hline Biomasa & 80,36 & 52,00 & 110,00 \\
\hline Solar & 221,09 & 215,00 & 225,00 \\
\hline
\end{tabular}

Fuente: MINEM

Las potencias adjudicadas corresponden a 162,3 MW hidroeléctricos, 142 MW eólicos, 27,4 MW biomasa, y 80 MW solares, lo que hace un total de 411,7 MW adjudicados. Las correspondientes energías adjudicadas son de 999,3 GWh/año a las hidroeléctricas y 887,3 GWh/año a las otras energías renovables no convencionales (eólica/biomasa/solar). En síntesis, se adjudicó una potencia total de 411,7 MW, que corresponden a una energía total de 1.886,6 GWh/año, a un precio medio de adjudicación de 81,2 US\$/MWh. Conforme al cronograma establecido en las bases, el 31 de marzo del 2010 se firmó con los postores adjudicatarios los correspondientes los contratos de suministro de electricidad con RER por un plazo de 20 años.

El Decreto Legislativo $N^{\circ} 1002$ revela la decisión política de trabajar por una matriz energética sostenible que ayude en el mediano y largo plazo a mejorar el desarrollo humano y a mitigar los efectos del cambio climático. Por ello se puede usar más y mejor el agua, los vientos, la energía solar, la biomasa, la geotermia y orientar el uso del gas disponible - que es un recurso no renovable y con reservas limitadas - al transporte, las viviendas, la industria, la petroquímica; asimismo, usar la tecnología del ciclo combinado en generación eléctrica, es decir. hacer un uso eficiente del gas, dándole valor agregado. No olvidemos que el gas del Lote 88 con precio promotor y 
regulado solo cubrirá plenamente la demanda al actual nivel de crecimiento hasta 2019 o máximo 2021; después tendrá que utilizarse para la atención de la demanda local de electricidad el gas de otros lotes, que tendrán precio internacional. Por ello considero que fue un error ministerial en 2009 la medida de anunciar, sin resolver el tema del Lote 88, que parte del gas del Lote 57 se orientara al mercado interno, cuando el compromiso original de Repsol en 2008, manifestado en carta de su principal directivo dirigida al ministro Juan Valdivia era al revés, utilizar este nuevo descubrimiento para liberar el gas del Lote 88 del compromiso de exportación. Esto finalmente ha sido corregido por la renegociación del gobierno de Ollanta Humala, con la restitución del Lote 88 para el mercado interno. Ahora, por el crecimiento de la demanda, se centra la atención en evaluar la necesidad de usar los recursos gasíferos del Lote 58.

Las distribuidoras y el conjunto de actores económicos del mercado deben comprometer su demanda futura de electricidad en las subastas especiales para hidroeléctricas y en las licitaciones de energías renovables alternativas. Si no se hace de esta manera, participan en las llamadas licitaciones ordinarias, que no son especiales para hidroeléctricas o para renovables no convencionales, favoreciendo que haya más generación térmica, es decir más demanda y consumo de hidrocarburos en el sector eléctrico.

Es muy difícil que puedan competir las hidroeléctricas con las centrales térmicas, por los montos de inversión significativamente mayores e el mayor tiempo de construcción y recuperación de la inversión, no obstante el factor de descuento. La mencionada Ley № 28832, establece que en las licitaciones se debe aplicar un factor de descuento de $15 \%$ a las ofertas económicas respaldadas con proyectos hidroeléctricos para efectos de su evaluación, toda vez que esos proyectos implican mayores costos de inversión que los proyectos térmicos. Comprometer la demanda eléctrica en el largo plazo a un horizonte más térmico no es lo mejor para el país, porque esa dependencia afecta el futuro y la competitividad de la minería, la industria y el conjunto de la economía nacional. A partir de 2020 se requerirá en el comercio mundial la certificación de huella de carbono en todo lo que el país exporte al mundo. Si no acreditamos menor huella o huella neutral, esto será una barrera para el acceso.

\section{Proyecciones para incrementar la participación de las energías renovables en la matriz energética}

En este acápite se identifican los principales componentes de la estrategia para incrementar la participación de las energías renovables en la matriz 
energética y las razones de un mercado regional energético que se asiente en las renovables. Se esboza una propuesta de política pública para un programa estratégico de desarrollo energético sobre la base de fuentes renovables y eficiencia energética.

En la nueva matriz energética sostenible (NUMES) trabajada por el equipo de expertos contratado por el Banco Interamericano de Desarrollo (BID) a pedido del gobierno peruano, dentro del convenio de la nueva matriz energética, se estima que a 2021 y con un crecimiento de la demanda de $7 \%$ anual, necesitaríamos $8.000 \mathrm{MW}$ adicionales de generación eléctrica. Cubrir esta cantidad sería posible si se ejecutaran dentro de los plazos previstos todos los proyectos actualmente en cartera, llegando incluso a tener una reserva técnica de 30\%; estos representan inversiones de hasta US\$13.000 millones. Sin embargo, una marcada debilidad institucional provoca retrasos en la ejecución de estos nuevos proyectos de generación causados por falta de planeamiento estratégico, cambios de los ministros de la cartera de energía, demoras en la licencia social, trámites del Estudio de Impacto Ambiental, y otras licencias y permisos, los cuales ponen en riesgo la disponibilidad de energía eléctrica en el corto plazo. Además, se identifica una creciente vulnerabilidad en el sistema actual que corresponde a que gran parte de la generación eléctrica se concentra en la central hidroeléctrica del Mantaro y en las plantas térmicas a gas ubicadas en la costa central -en el Callao y Chilca, cerca de Lima- que se abastecen de gas a través de un solo gasoducto. La concentración de la generación eléctrica, altamente dependiente de un solo gasoducto, agudiza el riesgo de desabastecimiento frente a cualquier incidente. En el largo plazo, la falta de un planeamiento estratégico y la precariedad de la gestión pública pondrían en riesgo la seguridad energética.

Adicionalmente se menciona en el referido estudio, llevado a cabo por el MEM y el BID, la vulnerabilidad de la matriz energética al cambio climático. Ya se han revelado datos preocupantes, como lo señala el propio estudio, en un escenario de un incremento limitado de la temperatura: «(...) centrales hidroeléctricas se verían afectadas por disminuciones en la precipitación (>20\%), las cuales en conjunto generarían una potencia de $1.014 \mathrm{MW}$, lo que representa aproximadamente el 3,9\% del total de la potencia a generar por las hidroeléctricas en los distintos planes al año 2040» (MEF 2012: 13) ${ }^{18}$

Además de eso, tenemos un problema adicional en la distribución. Salvo Lima e Ica, que tienen distribuidoras privadas, en el resto de las regiones las empresas de distribución son estatales. Las nuevas inversiones y negocios en estas regiones se ven limitadas porque las empresas de distribución

18 El trabajo NUMES del BID fue publicado por la Unidad de Coordinación de Préstamos Sectoriales del Ministerio de Economía y Finanzas. 
estatales están muy restringidas en su manejo corporativo y no están en capacidad de proveer electricidad a los nuevos proyectos o negocios, al no disponer o restringirse la disponibilidad de sus utilidades ${ }^{19}$.

Como hemos dicho, el precio de la energía se encuentra actualmente distorsionado con respecto al mercado internacional, principalmente por el precio regulado del gas que proviene del Lote $88^{20}$. Esto se identifica como una barrera para el desarrollo de proyectos alternativos de energías renovables y eficiencia energética. Si bien contar con precios bajos en el gas tiene beneficios de corto plazo en algunos actores como el acceso a energía para la población de menos recursos, se tienen consecuencias de largo plazo (no hay inversiones diversificadas, hay mayor vulnerabilidad, puede haber pérdidas) que no están siendo internalizadas en los costos actuales. Los precios bajos de la energía no son siempre necesariamente competitivos si no otorgan al inversionista una adecuada tasa interna de retorno; además, comparados con países vecinos como Chile y Colombia, pueden llegar a remunerar menos, lo que resulta en un desincentivo para el desarrollo de nuevos proyectos de generación.

A pesar que nuestro riesgo-país se encuentra en niveles históricamente bajos, los inversionistas de este rubro buscan tasas de retorno más altas ${ }^{21}$, básicamente porque hay más dificultades en el proceso de desarrollo de los proyectos y porque existe la percepción de que contamos con una gestión o gerencia pública muy deficiente, aparte de los problemas de seguridad, como es el caso de la zona del VRAEM, próxima a las instalaciones del sistema de transporte y bombeo del gas de Camisea.

Existe poca información de parte del Estado en relación con las proyecciones de demanda y la mejor forma de asegurar la oferta eléctrica. La planificación energética de largo plazo no se cumple, no es vinculante, salvo en la transmisión, lo que resta predictibilidad al sector eléctrico. Esta situación de incertidumbre es también un factor que desanima a los inversionistas y la falta de inversiones oportunas pone en riesgo la seguridad energética del país. Cabe mencionar como ejemplo que la segunda subasta para proyectos de generación con energías renovables no convencionales

\footnotetext{
19 El año 2010 se transfirió fondos del Fondo Nacional de Financiamiento de la Actividad Empresarial del Estado (FONAFE) para pagar parte de la deuda del Fondo de estabilización de los precios de los combustibles.

${ }^{20}$ En el Contrato del Lote 88 se establece un precio regulado del gas para el sector eléctrico en el mercado interno y otro mayor para otros usos. Esto guardaba sentido en 2004, por cuanto había un déficit crítico de oferta eléctrica, pero ahora la situación ha cambiado y se corre el riesgo de excesiva dependencia del gas en el mercado eléctrico, habiendo opciones como el uso del agua, que nos alargaría la vida útil del gas como recurso no renovable.

${ }^{21}$ Nuestra Ley de Concesiones Eléctricas habla de garantizar una rentabilidad no menor al $12 \%$.
} 
tuvo cambios desalentadores en el nuevo reglamento y exigió mayores requisitos que lo solicitado en la primera subasta. Las exigencias actuales para estos proyectos, como es el caso de las fianzas bancarias, son similares a las que cumplen los grandes proyectos de generación.

Además existen otros inconvenientes, como algunos casos de proyectos de energías renovables, en particular pequeñas hidroeléctricas en los que la calidad de los estudios de prefactibilidad no es la mejor y luego de adjudicados se dan cuenta que no tienen suficiente caudal para cubrir la energía ofrecida. Esto genera que el MEM pierda confianza en este tipo de proyectos y debilita su promoción.

Ya hemos comentado que existen problemas de limitaciones del sistema eléctrico, en la convergencia de tecnologías renovables intermitentes como la energía solar o eólica y la capacidad y tecnología del sistema de transmisión. Además El Comité de Operación Económica del Sistema Interconectado Nacional (COES), centro de operaciones de despacho de la energía, todavía no tiene un sistema automatizado para el despacho de la electricidad; por ello es particularmente reacio a más participación de las energías alternativas y argumenta que la intermitencia de algunas tecnologías renovables pone en riesgo la confiabilidad del sistema, aunque en realidad sus propios estudios demuestran que pueden operar energía intermitente hasta aproximadamente un 20\% del total de la energía que se comercializa.

Intermitentes son el viento y el sol, en la tecnología fotovoltaica, pero las tecnologías renovables son también la biomasa o la geotermia, que operan las 24 horas del día y tienen una eficiencia superior al uso de energía de origen fósil. En el Perú tenemos potencial de energías renovables alternativas, especialmente de pequeñas hidroeléctricas, vientos, energía solar, geotermia y biomasa. La energía solar fotovoltaica es una alternativa bastante económica y adecuada para sistemas aislados. Las energías renovables, generación eólica, pequeñas hidroeléctricas y la biomasa, son una solución muy competitiva. Si cumpliéramos el objetivo de contar con $5 \%$ de la electricidad generada por fuentes renovables no convencionales, se estima que sería necesario contar con 1.400MW instalados al 2021. Si tenemos a la fecha entre 500-600MW ya instalados, quedarían pendientes de instalar más de 700MW.

La nueva matriz energética sostenible, propuesta por el MEM con el apoyo del BID, trata de identificar cuál debería ser la matriz energética al 2040. Se plantea que para este plazo las renovables puedan cubrir el $20 \%$ de la generación. Se estima también que para lograr los objetivos planteados se requieren inversiones de hasta US $\$ 85.000$ millones, de los cuales US $\$ 25.000$ serían para proyectos de generación y de estos, US \$9.000 millones serían para 
proyectos de energías renovables en sistemas centralizados o conectados a la red.

Para llevar adelante una transición energética hacia una mayor participación de las energías renovables alternativas, paralelamente se pueden aprovechar con eficiencia los recursos no renovables como el gas natural, que va a acompañar la transición durante por lo menos veinte años. Lo importante sería fijar claramente el camino de la transición. Se plantea como estrategia de financiamiento el sincerar e incrementar gradualmente el precio del gas para uso eléctrico y con esto crear un fondo que permita cubrir el costo de un portafolio de proyectos de energías renovables alternativas y eficiencia energética, como parte de la nueva infraestructura energética requerida.

En cuanto a la eficiencia energética, en el Plan Nacional de Eficiencia Energética $^{22}$ se estima que ahorros de un 5\% en el consumo energético reducirían la demanda de electricidad en $300 \mathrm{MW}$, lo que equivale a una central de gas natural (inversión de US\$200 millones) o una central hidráulica (US\$600 millones). Todavía tenemos potencial de ahorro incluso con bajas inversiones; se ha determinado mediante estudios que en sectores como el agrario (específicamente el lácteo) se pueden lograr ahorros de energía hasta del 30\% con una baja inversión. Se podría, entonces, financiar un plan de eficiencia energética de corto plazo cubriéndolo con un ligero incremento de las tarifas eléctricas.

En transmisión se trata de constituir anillos energéticos regionales, superar el sistema lineal o radial actual que nos hace absolutamente dependientes de una sola línea, porque no hay otras alternas. El paso a sistemas inteligentes de transmisión puede comenzar por el centro de demanda del país, particularmente en Lima, la capital.

\subsection{Exportación de electricidad}

El país no puede limitarse a analizar solo cómo producir energía para el consumo interno. Nuestro gran potencial de renovables nos indica que podemos exportar electricidad y así mejorar la infraestructura y valorar las ventajas de la economía de escala, y pensar en las oportunidades de un mercado más grande de energía atendido con fuentes inagotables. Las energías renovables pueden atender la demanda de países vecinos, como es el caso de Chile, apoyando su demanda nocturna de electricidad; es una oportunidad

${ }^{22}$ Me refiero al Plan Nacional de Eficiencia Energética que se elaboró en 2007, fijando objetivos y metas. 
para mejorar la actual situación de nuestra infraestructura (IPE 2009) ${ }^{23}$, el déficit que hoy tenemos y que resulta una gran barrera para un desarrollo más equilibrado en todas las regiones ${ }^{24}$. El Perú podría convertirse en un hub energético andino en el mediano y largo plazo, priorizando siempre cubrir antes su consumo interno. Tenemos el potencial para hacerlo, pero sería un error comprometerse a exportar gas como materia prima, siendo un recurso no renovable, por lo menos con el actual nivel de reservas probadas; eso sería repetir la experiencia negativa del acuerdo de suministro con gas de Argentina a Chile.

El sector privado puede tener una participación más activa y protagónica. Para el Perú el reto es superar el déficit de infraestructura y para ambos países, Chile y Perú, se trata de lograr el empoderamiento de las energías renovables y ganar en seguridad energética. Podrían participar, por un lado, los grandes operadores de la industria minera, asegurando la compra de la energía que sus proyectos requieren y viabilizando así las inversiones en generación eléctrica de las empresas generadoras; asimismo, considerando que el Estado se centra actualmente en abastecer al sector regulado, el sector privado puede organizar su demanda ${ }^{25}$ y solicitar que esta sea cubierta utilizando el mecanismo de subasta de largo plazo (ya sea con energías renovables alternativas o con hidroeléctricas ${ }^{26}$.

Condiciones fundamentales para lograr esto son: saber negociar un acuerdo especial con Chile, la voluntad política y la mejor capacidad de gestión. No se puede trasladar el subsidio al gas del Lote 88 que hoy beneficia al sector eléctrico nacional y tampoco podemos pedir precios que no sean

${ }^{23}$ El estudio El Reto de la Infraestructura el 2018, realizado por encargo de AFIN y publicado por el Instituto Peruano de Economía (IPE 2009) estima que la inversión en infraestructura básica que debe realizar el Perú en un horizonte de diez años para crear las condiciones necesarias que permitan el desarrollo sostenible y de largo plazo del país asciende a US\$ 37.760 millones, cifra que representa 30\% del PBI.

${ }^{24}$ En muchas regiones del interior el servicio público de electricidad es muy deficiente.

${ }^{25} \mathrm{Si}$ el sector privado de nuestros países suma todas sus necesidades energéticas, se organiza la demanda, lo que puede empujar y acelerar las subastas de largo plazo, los grandes compradores de energía asumen un rol proactivo.

${ }^{26}$ Las grandes hidroeléctricas son cada vez más difíciles de construir, por las restricciones sociales y ambientales que señala la Comisión Mundial de Represas del Banco Mundial. La Comisión Mundial de Represas (WCD) fue establecida por el Banco Mundial y la Unión Mundial para la Naturaleza (UICN) en mayo de 1998 en respuesta a la creciente oposición a las represas grandes. «Las represas grandes han obligado a abandonar sus hogares y tierras a 40-80 millones de personas, con impactos que incluyen extremos sufrimientos económicos, la desintegración de sus comunidades, y un incremento en sus problemas de salud mental y física. Las comunidades indígenas, tribales y campesinas han sufrido de manera desproporcionada. Las personas que viven río debajo de los embalses también han sufrido por enfermedades transmitidas por el agua y la pérdida de los recursos naturales de los cuales dependían para ganarse el sustento» (Aviva et alt. 2002: 2). 
competitivos. Es necesario contar con capacidad de gerencia y decisión política que lleven a un planeamiento energético de corto, mediano y largo plazo, que sea concertado con los empresarios privados y que involucre a otros sectores como el académico y la sociedad civil. Hay que dimensionar el terreno que puede ganarse en calidad ambiental y en salud en nuestras economías. Sobre la base de este planeamiento, se puede llegar a una hoja de ruta que sea pública, concertada y clara, de la cual se rinda cuentas de manera periódica y transparente, precisando los avances.

Las energías renovables (en comparación con el gas natural) tienen un mayor costo inicial y en ese sentido, las reglas para promocionarlas se plasman en concursos independientes por tipo de tecnología, a partir de la priorización de las que tienen menor costo de operación y mayor eficiencia, como el factor de planta. Actualmente un proyecto de renovables tiene que cumplir casi las mismas condiciones que el resto de proyectos.

Se discute el uso de subsidios, pero hay que tener en cuenta que si Europa no ha podido todavía liberar el mercado de renovables, de una tarifa garantizada, menos lo pueden hacer el Perú o Chile, países donde recién está naciendo el mercado de renovables alternativas. No se puede abandonar la promoción de renovables; las bondades demostradas en Europa y ahora en Sudamérica, sobre la base de una cuota del mercado y precios garantizados es un camino que ha mostrado resultados positivos ${ }^{27}$. De no hacerlo, se corre el riesgo de regresar a un escenario de total dependencia al petróleo y el carbón, donde la nueva oferta eléctrica pase toda al uso de combustibles fósiles y para evitarlo es necesario contar con las subastas especiales por tecnología.

Además, se requiere un sistema de transmisión más grande, bidireccional, confiable e inteligente y modernizar el centro de despacho, que sea automatizado y pueda responder a la intermitencia propia de algunas fuentes renovables. Para todo ello es necesario sincerar el precio de la energía de manera gradual, para evitar distorsiones y retrasos en las inversiones que provocan luego impactos traumáticos. Asimismo, los precios de los nuevos yacimientos de gas natural pueden sincerar la oferta eléctrica a base de gas, para que las hidroeléctricas y otras alternativas renovables sean cada vez más competitivas. Todos estos argumentos nos ayudan a entender la relevancia del estudio de este tema y lo que está en juego.

En nuestro país, por la debilidad institucional reinante y para que las leyes sean cumplidas, se necesita planeamiento estratégico, voluntad y

${ }^{27}$ Los problemas de seguridad energética, el cambio climático, el potencial para la exportación, menores costos, proporcionan un terreno adecuado para el despegue de tecnologías limpias, hecho que se corrobora por los recientes resultados de subastas en el mundo, donde los precios de la energía solar fotovoltaico han llegado a niveles históricos. 
continuidad política para ejecutar una ley específica, como es el caso de la política de Estado en materia de energía que dispone se diversifique la matriz y se reduzcan vulnerabilidades. Una vulnerabilidad es la dependencia en el petróleo, que importamos mayoritariamente. La economía peruana depende en $72 \%$ de los hidrocarburos. No es sostenible depender excesivamente de un recurso no renovable; se trata de lograr seguridad energética y un abastecimiento sostenible de los recursos energéticos, que nos permita ir hacia una economía que crezca, generando desarrollo humano y menos emisiones.

La debilidad del Estado guarda directa relación con la falta de uso de una herramienta fundamental, el planeamiento estratégico y la ausencia de políticas de Estado. Es decir, no es común encontrar claramente definidos objetivos de corto, mediano y largo plazo, que estos se cumplan y haya el monitoreo necesario.

Para garantizar resultados sostenibles que permitan cumplir las leyes promotoras es necesario el seguimiento y evaluación de las políticas públicas o formas de accountability a través del trabajo organizado de la sociedad civil, monitorear el planeamiento estratégico hoy todavía inexistente en la gestión pública.Como hemos dicho, una primera política energética es la diversificación de la matriz energética, que parte del estudio de la problemática vigente: una línea base que nos permita conocer el potencial país en las distintas fuentes de energía y sus costos de operación. Después de un análisis costo-beneficio, es factible utilizar las tecnologías más limpias, tomando en consideración su menor costo y la disposición del recurso renovable.

\subsection{Gas natural}

El gas es el hidrocarburo menos contaminante, es una fuente secundaria que permite reducir eficientemente emisiones en el sector transporte, industria y hogares, por lo que puede orientarse su uso hacia estos sectores procurando que las energías renovables sustituyan gradualmente al petróleo en la generación eléctrica, donde el gas no es la única opción. Además, la generación térmica a gas puede utilizar la tecnología del ciclo combinado, para aprovechar al máximo posible el recurso no renovable y su poder calórico.

Se trata de hacer un uso eficiente del gas como recurso no renovable, de darle valor agregado. También se trata de poner límites a su crecimiento por encima del $40 \%$ de la capacidad de generación eléctrica con este recurso. Esto se justifica técnicamente al tener disponibles recursos energéticos renovables, que al ser eficientemente utilizados nos permiten evitar la sobreexplotación del gas, evitando que se agote de forma más rápida, por su condición de recurso no renovable. 


\subsection{Eficiencia energética}

El diseño de políticas de eficiencia energética es considerado hoy una energía renovable más y puede traer consigo reducción de costos y emisiones por manejo de tecnologías modernas y adecuado uso de los recursos. La energía que ahorramos es energía que damos a sectores que todavía no logran acceso a la misma; desde las cocinas mejoradas en zonas rurales aisladas que evitan la enfermedad de muchos pobladores por respirar gases contaminantes en lugares cerrados, hasta el uso de focos LED con garantía de fábrica que permiten un $95 \%$ de ahorro. Asimismo, profundizar la reforma del transporte público en el país con el uso mayor del bono del chatarreo y un plan agresivo de racionalización y modernización del parque vehicular; en la capital del país, tener nuevas líneas del sistema metropolitano de buses a gas y el tren eléctrico, aparte de promover más el uso de autos a gas. También ha llegado el momento de comenzar proyectos piloto con unidades híbridas, vehículos menores que usan baterías eléctricas y con ello se reduce sustancialmente el consumo del combustible fósil. Otra medida importante es el etiquetado en equipos y materiales de construcción para promover el uso de materiales amigables con el medioambiente en edificios y viviendas; el etiquetado también es importante en equipos, máquinas y electrodomésticos, donde la persona puede conocer el rendimiento más eficiente y su menor costo de operación. Todas son tareas necesarias de ejecutar dentro del desarrollo de varios mecanismos de desarrollo limpio programáticos. En el Perú falta el tan esperado etiquetado en todo bien o equipo que se adquiera, para que el consumidor esté orientado y el establecimiento de límites mínimos de eficiencia en producción y consumo de energía.

En la formulación de los balances regionales y nacionales de energía, el inventario de emisiones evalúa, verifica y monitorea los avances del plan maestro de energías renovables y eficiencia energética para el sector moderno y para las zonas rurales, y cumplir de una vez el mandato de la ley de renovables, de desarrollar un plan de energías renovables específico para la atención del sector moderno de la economía nacional, el Sistema Interconectado Nacional. Ser más agresivos en la tarea de capacitar a los agentes económicos en eficiencia, ahorro de energía y uso de energías renovables, con capacitación técnica y dación de líneas de crédito.

Asimismo, el reglamento actual de electrificación rural obliga a que el $1 \%$ de cada presupuesto se destine a capacitar en los usos productivos a la población beneficiada con el acceso a la energía; esto puede optimizarse desarrollando una hoja de ruta, de la mano con instrumentos como la concesión eléctrica rural de creación el año 2006 y el uso mayoritario para el sector rural del subsidio cruzado Fondo de la Compensación Social Eléctrica 
(FOSE), incorporado en la tarifa eléctrica desde 1991 pero orientado durante muchos años solo a la población pobre urbana. El FOSE está dirigido a favorecer el acceso y permanencia del servicio eléctrico a todos los usuarios residenciales del servicio público de electricidad cuyos consumos mensuales sean menores a 100 kilovatios hora por mes comprendidos dentro de la opción tarifaria BT5, residencial o aquella que posteriormente la sustituya.

Se trata de orientar el desarrollo de la industria con el avance de los límites máximos permisibles, sobre la base de la adopción de los mejores estándares internacionales; por ejemplo, el monitoreo y eficaz control para lograr aire limpio, un riguroso cumplimiento del tantas veces postergado cronograma de reducción del contenido de azufre en el diésel y las gasolinas, un estricto cumplimiento del Índice de Nocividad de los Combustibles (INC) que orienta la tributación a gravar menos a los combustibles más limpios incorporando la emisión de GEI en su formulación.

El rediseño del plan de electrificación rural buscando un uso mayor y más eficiente de los recursos energéticos renovables, es una solución eficaz a la falta de acceso a la energía de casi cuatro millones de personas, teniendo presente que existen 40.000 pequeños centros poblados aislados, donde difícilmente va a llegar la red de distribución convencional. La capacitación en operación y mantenimiento de paneles solares y otros equipos con tecnologías renovables y los usos productivos es clave para estimular la configuración o desarrollo de mercados locales y la formación de cadenas productivas (articular cocinas mejoradas, viviendas bioclimatizadas, uso de energías renovables en invernaderos, cobertizos de animales, bombas de agua, entre otros). Todo esto permite el objetivo de la ley, mejorar la calidad de vida de la población, diversificando la matriz energética y brindando seguridad energética.

\section{Diversificación de la matriz energética}

El evitar que se pierda lo ganado en la reducción de la pobreza, el acceso a la energía y una mejor calidad del servicio público de electricidad, obligan a una gestión más eficiente en la energía. La estrategia de mitigación y adaptación posibilita una más agresiva diversificación de la matriz energética con metas precisas en el corto, mediano y largo plazo, donde los instrumentos de gestión ambiental se articulen con la promoción del desarrollo humano y el desarrollo de una economía baja en carbono, fomentando el uso de energías limpias en la nueva oferta eléctrica y en el desarrollo de cualquier emprendimiento. Esto crea oportunidades que antes no tenían los ciudadanos. Pero no solo se limita el campo eléctrico, también es política energética lograr un sistema de transporte más seguro y menos contaminante. No tiene sentido que el 
principal combustible de consumo nacional sea el diésel en un país que se ufana de tener gas natural y renovables. Esto es por lo menos, contradictorio.

Para ello tiene que existir relación y coherencia con las políticas transversales de promoción de la inversión, la política tributaria, la generación de empleo, la política regulatoria, y la política de ordenamiento territorial y de evaluación ambiental estratégica. Aquí la tarea corresponde a los tres niveles de gobierno: nacional, regional y local, pero compromete al conjunto de la sociedad civil, lo que involucra a la academia y a la empresa privada. Ellas han mostrado ser más creativas e innovadoras que el Estado, sobre todo, cuando se trata de acceder a la energía utilizando energías más limpias y en lo posible, renovables.

La política energética tiene gran importancia para la gestión del desarrollo humano, más aún cuando hoy vivimos amenazas, contaminación y el cambio climático, que también nos exige diversificar la matriz para ser menos vulnerables. La meta voluntaria comprometida por el Perú ante Naciones Unidas es lograr un $40 \%$ de participación de las energías renovables para el año 2021. Esto ha sido criticado como inviable y poco serio. Lo cierto es preguntarnos si lo podemos hacer. En el sector eléctrico es factible, pero se necesita el cambio en transporte, en la industria y en los hogares. Si somos capaces de construir la hoja de ruta, esto nos encamina hacia un desarrollo sostenible, mejorando la calidad de vida de la gente y democratizando gradualmente el uso y acceso a la energía.

Hoy, paradójicamente, se mantiene la dependencia del petróleo y sus principales derivados, han aumentado los volúmenes de importación de crudo y diésel, llegando a estar cerca de los 5.000 millones de dólares anuales ${ }^{28}$. Esto provoca contaminación, no favorece la calidad de vida y la población lo percibe. Por falta de una política articulada que cuide la dimensión social y ambiental ${ }^{29}$ se generan sobrecostos y se pierden muchas oportunidades por la justificada desconfianza de la población, y se paga un costo alto por la contaminación y deterioro creciente de los ecosistemas. Lo cierto es que no hay un adecuado manejo de la política energética sobre combustibles, no hay política de manejo de los residuos y subsisten problemas graves de deforestación por el desborde de la minería ilegal y el narcotráfico. Según el Banco Mundial, este deterioro ambiental compromete en el caso peruano al

\footnotetext{
${ }^{28}$ En 2008 la cifra llegó a 2.500 millones de dólares; es decir, la dependencia se ha incrementado, no obstante, el ingreso del gas natural a la economía.

${ }^{29}$ Los Estados enfrentan diversos problemas, uno de ellos es el de fortaleza institucional, como en el caso peruano, que a nivel sectorial o del Centro de Planeamiento (CEPLAN) producen documentos de planeamiento que no se respetan o siguen, así limitan el diseño e implementación de una estrategia en materia energética y de sostenibilidad, como viene ocurriendo.
} 
3,9\% del PBI. Esto afecta los espacios rurales y entornos urbanos, que sufren la degradación ambiental; lo testimoniamos todos los días en los sistemas de transporte y agua, entre otras actividades prioritarias, como el irresponsable manejo de las aguas servidas que provocan la contaminación del agua. En las áreas rurales, se aprecia la contaminación del aire en interiores, donde una simple acción de mejora en la forma de cocción de los alimentos puede llevar a salvar miles de vidas con el uso de chimeneas y un aprovechamiento más eficiente de la leña o bosta. Problema grave también es la degradación de suelos ( $23 \%$ de los suelos ya han sido desertificados), la deforestación y la proliferación de enfermedades por acumulación abierta de residuos.

Todo este panorama crítico nos lleva a pensar si podemos seguir tolerando la pérdida continua de calidad de vida por prácticas que ya no son toleradas en el mundo moderno. El uso de energías limpias es una forma eficaz, pero parcial de enfrentar y corregir estos errores. El cambio climático agrava este escenario y hace urgente la formulación de políticas públicas más eficaces y claras, que nos aseguren poder cumplir los objetivos del milenio y nuestros compromisos voluntarios unilaterales con la Comisión Mundial de Cambio Climático, en el marco de las Naciones Unidas.

El uso de energías limpias nos ayuda a mitigar los efectos del cambio climático, que en el Perú se estima que comprometerán el 4,5\% del PBI a 2025, según estudio realizado por Bruno Seminario de la Universidad del Pacífico (2008). Por ello, un aspecto relevante es nuestra vulnerabilidad frente a los impactos del cambio climático, no obstante ser como país un causante menor de las emisiones mundiales de gases de efecto invernadero. Actualmente el impacto ya se siente, los glaciares han retrocedido un $40 \%$ en los últimos 40 años afectando la disponibilidad de agua; los modelos de escenarios climáticos indican que el Fenómeno del Niño o la Niña podrán ser más intensos y más frecuentes (históricamente han ocurrido aproximadamente cada cincuenta años), hoy vemos uno por década (1983 y 1997); se ha percibido también un aumento en la recurrencia de sequías y heladas en cuencas de gran importancia por ser proveedoras de alimentos.

Como lo confirman las comunicaciones nacionales del Ministerio del Ambiente $^{30}$ sobre la política pública sobre el cambio climático, el país tiene un alto grado de vulnerabilidad ante los desastres naturales y el cambio climático. Por ello, hay un imperativo de ejecutar una estrategia de mitigación y adaptación frente al cambio climático. Parte indispensable de esa estrategia es luchar contra la pobreza, empoderando a los más pobres; fortalecer

${ }^{30}$ En la página web del Ministerio del Ambiente se pueden encontrar las dos comunicaciones nacionales sobre cambio climático, que están en proceso de implementación; se encuentra en elaboración la tercera comunicación. 
la infraestructura, y reducir la huella de carbono, promoviendo el uso de energías limpias, diversificando la matriz energética y descentralizando la generación, lo que se conoce como generación distribuida.

Por la creciente amenaza, resulta fundamental informar del inventario de riesgos, costos de la polución y la magnitud posible del daño que ya está generando y va a generar el cambio climático, y medir así las consecuencias de no actuar a tiempo. Todo ello sirve para que se elabore la propuesta de estrategia y plan de acción, que involucre como política relevante el desarrollo y mayor de uso de energías renovables en la matriz energética a partir de un planeamiento estratégico, identificando los lineamientos de política y las propuestas fundamentales de los programas para su implementación, considerando metas de avance concreto de estas fuentes en la matriz energética.

Además, el Perú tiene amplios sectores rurales aislados de su población a quienes no llegan los servicios básicos como la energía y se encuentran en situación de extrema pobreza. Eso hace más relevante la política de promoción del uso de energías renovables, porque las características de estas tecnologías, al tener costos menores por hogar conectado que el tendido de líneas convencionales, hace más rápidamente viable el acceso de más hogares rurales a la energía, lo que permite luego de la necesaria capacitación el uso de la energía para fines productivos y así generar excedentes, por más lejano que se encuentre un centro poblado ${ }^{31}$.

En el caso específico del Perú subsisten grandes brechas sociales, a los que se suman los problemas de falta de capacidad institucional, capacidad de gestión, planeamiento y asignación de recursos en todos los sectores y niveles de gobierno. Por ello es necesario fortalecer la gestión pública y la capacidad institucional en el marco del proceso de descentralización y modernización del Estado; donde la descentralización es entendida como un proceso económico y técnico de construcción de capacidades locales y regionales, no solamente mayor presupuesto o transferencia de competencias. Esto a su vez va de la mano con el desarrollo de sistemas de monitoreo y evaluación de las políticas y normas, con sistemas de accountability o monitoreo de resultados.

Paralelamente, hay que fortalecer los mecanismos de participación ciudadana en la gestión del Estado para ir aceleradamente a una gestión por resultados y promover sostenibilidad a partir de una mejor competitividad y productividad, entendida como la facilitación de la infraestructura dentro de un proceso productivo más limpio y sustentable, tomando en consideración los criterios de huella ecológica en las actividades productivas.

31 Esto es reconocido en el Plan Nacional de Electrificación Rural de 2016. 
Adelantando algunas primeras conclusiones, se trata de promover las ventajas de la diversidad biológica y la configuración del territorio; tareas como actualizar y valorar el inventarío de recursos naturales renovables, los conocimientos tradicionales y los servicios ambientales. Asimismo, promover y afianzar sostenidamente alianzas estratégicas tripartitas Estado-universidad-empresa; promover energías limpias, con un trato respetuoso de los ecosistemas y afianzar la labor de un Estado moderno y más transparente articulado por la meritocracia a todo nivel y el desarrollo de capacidades científicas y tecnológicas. Además, aprovechar las ventajas de la economía de escala y de compartir eventualmente infraestructura con países vecinos, donde exista algún grado de complementariedad ${ }^{32}$, como parte de los procesos de integración hoy en curso.

Es importante, considerar la transversalidad de la gestión del Estado, en un país que quiere ser sustentable, e involucrar a todos los sectores productivos y extractivos, el sistema educativo y la propia seguridad nacional. Del fortalecimiento de la institucionalidad depende la propia gobernabilidad y obviamente la seguridad en sus distintas facetas: ambiental, alimentaria y energética, que son los indicadores de cuánto un sistema es capaz de hacer frente a los problemas y las amenazas, como la contaminación o el cambio climático.

Con la aprobación de los Decretos Legislativos N 1002 y N 1041 en el año 2008, el Perú abrió el camino a las energías renovables alternativas. A partir de la experiencia ganada en el proceso de implementación de estas normas, se han desarrollado casos o proyectos de operación de energías renovables alternativas que marcan un hito inicial, venciendo las dificultades, los lobbies y los intereses que trataron de resistirse al proceso de cambio. Vamos a presentar uno de los casos más relevantes como demostración de la viabilidad de una política pública que promueva el uso de las tecnologías renovables.

Los últimos y únicos dos concursos de generación eléctrica para energías renovables alternativas realizadas por OSINERGMIN al amparo del Decreto Legislativo $\mathrm{N}^{\circ} 1002$, demuestran que en el Perú los costos de la generación eléctrica con hidroenergía, eólica y biomasa, están actualmente en un rango competitivo en comparación con los costos de generación con fuentes fósiles. Mientras tanto, la energía solar, se acerca cada vez más al nivel de competitividad en relación con otras fuentes de energía.

El Plan Bicentenario a 2021 del Perú, aprobado por Decreto Supremo $\mathrm{N}^{\circ}$ 054-2011-PCM, establece como objetivo el desarrollo sostenido del país.

${ }^{32}$ Es sabido que cuando llueve en Colombia, en el Perú estamos en período de estiaje, por lo que la integración de la infraestructura energética sería una ventaja económica para ambas naciones. 
Para tal efecto, se plantea el aseguramiento, entre otros, de los insumos energéticos necesarios para viabilizar su realización, para lo cual la ampliación de la capacidad instalada para la generación y distribución de energía eléctrica (con énfasis en la diversificación de la matriz energética nacional y laintegración regional), resulta una política de estado fundamental.

Un aspecto que genera inquietud, es que se esperó mucho tiempo para convocar a una nueva tercera subasta y ahora está ocurriendo lo mismo para la quinta subasta. Los temas de energías renovables están siendo asumidos de manera errática, particularmente en el Perú, falta predictibilidad. Esto afecta la eficacia de una política pública que ha sido instrumentalizada por medio de una norma con rango legal ${ }^{33}$.

\section{Referencias}

Aviva Imhof, Susanne Wong y Peter Bosshard (2002). Guía Ciudadana sobre la Comisión Mundial de Represas. California: International Rivers Network / Red Internacional de Ríos.

Banco Mundial (2007). Análisis Ambiental del Perú (AAP): Retos para un Desarrollo Sostenible. Lima: Banco Mundial. Recuperado de: http://bibliotecavirtual. minam.gob.pe/biam/bitstream/handle/minam/1712/BIV01483. pdf?sequence $=1 \&$ isAllowed $=y$

Bosselmann, Klaus (2015). O princípio da sustentabilidad. Transformando direito y governança. Traducción, Phillip Gil França. São Paulo: Revista dos Editores.

Cenergia (2004). Plan Nacional de Electrificación Rural (PNER). Propuesta. Lima: CENERGIA.

\footnotetext{
${ }_{33}$ Mediante Decreto Legislativo $\mathrm{N}^{\circ} 1088$ se creó el Sistema Nacional de Planeamiento Estratégico y el Centro Nacional de Planeamiento Estratégico (CEPLAN), orientados al desarrollo de la planificación estratégica como instrumento de gobierno, tarea necesaria y paradójicamente ausente en el Perú. Entre las funciones a desarrollar, se encuentra la promoción de programas y proyectos prioritarios de desarrollo nacional. Para concretar este objetivo se conformó el Comité Multidisciplinario Plataforma de Agua y Energía para el Desarrollo Sostenible, el mismo que recoge los aportes de diferentes instituciones para perfilar la propuesta de matriz energética nacional de largo plazo. Conforme lo señalan los expertos, el crecimiento económico que viene experimentando el país en los últimos años, basado en el mayor precio de las materias primas, corresponde a una etapa favorable cuyo horizonte temporal se extenderá probablemente hasta mediados de la década de $2030 \mathrm{y}$, en consecuencia, hay que tomar las previsiones necesarias para asegurar el desarrollo sostenible, en lo que a dotación de infraestructura de energía se requiera. El problema es que la realidad no evidencia el cumplimiento por parte del Estado del planeamiento estratégico y dista del cumplimiento de lo dispuesto en las propias normas vigentes.
} 
CEPAL (2009). Contribución de los servicios energéticos a los objetivos de Desarrollo del Milenio y a la mitigación de la pobreza en América Latina y el Caribe. Santiago de Chile: NU. Recuperado de: http://repositorio.cepal.org/bitstream/ handle/11362/3720/S2007029_es.pdf?sequence=1\&isAllowed=y

CEPAL (2015). Panorama de la Inserción Internacional de América Latina y el Caribe. La crisis del comercio regional: diagnóstico y perspectivas. Santiago: NU.

CEPAL (2016a). Estudio Económico de América Latina y el Caribe. La Agenda 2030 para el Desarrollo Sostenible y los desafíos del financiamiento para el desarrollo. Santiago de Chile: NU.

CEPAL (2016b). Evaluaciones del desempeño ambiental del Perú. Aspectos destacados y recomendaciones. Santiago de Chile: OCDE/CEPAL. (2016c). Horizontes 2030: La igualdad en el centro del desarrollo sostenible. Santiago de Chile: CEPAL.

CEPAL (2016d). Segundo Informe Económico Anual 2016. Economías de América Latina y el Caribe. Recuperado de: http://www.cepal.org/sites/default/files/pr/ files/tabla_proyecciones_ee_americalatinaycaribe_2016_final-esp.pdf. Fecha de consulta: 30 de julio de 2016.

Centro nacional de Planeamiento Estratégico (2011). Plan Bicentenario. El Perú hacia el 2021. Lima: CEPLAN.

COES (2015). Producción con recursos renovables del SEIN. Lima: COES. Recuperado de http://www.coes.org.pe/Portal/Publicaciones/Estadisticas/. Fecha de consulta: 6 de agosto del 2016.

COES (2016). Producción hidroeléctrica y recursos hídricos. Lima: COES. Recuperado de http://www.coes.org.pe/Portal/Publicaciones/Estadisticas/. Fecha de consulta: 6 de agosto de 2016.

ComunidAd ANDina (CAN) (2008). El cambio climático no tiene fronteras. Impacto del cambio climático en la Comunidad Andina. Coordinador, Carlos Amat y León. Lima: CAN.

El Peruano, Diario Oficial (2010). Decreto Legislativo № 1002. Sobre la promoción de la inversión para la generación de electricidad con el uso de energías renovables. Lima: Diario Oficial el Peruano. (2013). Decreto Supremo $N^{\circ} 020$ 2013-EM. Reglamento para la Promoción de la Inversión Eléctrica en Áreas No Conectadas a la Red. Lima: Diario Oficial el Peruano.

EY (2016). «Renewable energy country attractiveness index RECAI. Building a better working world». Ernst \& Young Global, Issue 46, febrero.

Fondo de Población de las Naciones UnidAs (2015). Annual Report 2015. For people, planet \& prosperity. New York: UNFPA.

Foy VAlEnCia, Pierre (2013). «Estimativas y prospectivas sobre el sistema jurídico ambiental peruano post-Rio +20». Derecho PUCP. Revista de la Facultad de Derecho, N 70, 25-44. Lima: PUCP. Recuperado de http://revistas.pucp.edu. pe/index.php/derechopucp/article/view/6742/6859

FRIEDMAN, Thomas (2010). Quente, Plano e Lotado. Os desafios e oportunidades de um novo mundo. Traducción, Paulo Afonso. Río de Janeiro: Editora Objetiva. 
Friedrich Ebert Stiftung (2015). Matriz energética en el Perú y energías renovables. Lima: Sinco Editores.

Gamio Aita, Pedro (2010). Energía en el Perú: hacia dónde vamos. Lima: Fundación Ebert.

García Bustamante, Henry (2013). Barreras para el desarrollo de la bioenergía. Lima: Fundación Ebert.

Horn, Manfred (2007). Panorama de las energías renovables en el Perú y el mundo. Conferencia presentada en el XIV Simposio Peruano de Energía Solar - XIV SPES. Cusco, noviembre.

InTERnAtionAl EnERgy AgEnCy (IEA) (2016). Energy Technology Perspectives 2016. Paris: IEA. Recuperado de http://www.iea.org/Textbase/npsum/ ETP2016SUM.pdf. Fecha de consulta: 5 de agosto de 2016.

InSTituto NaCional De Estadística e Informática (2007). Censo Nacional 2007: XI de Población y VI de Vivienda (CPV 2007). Lima: INEI. Recuperado de http:// www.inei.gob.pe/sistemas-consulta/http://ineidw.inei.gob.pe/ineidw/

Instituto NACIONAL DE Estadística e Informática (2015a). Estado de la población peruana 2015. Lima: INEI: Recuperado de https://www.inei.gob.pe/media/ MenuRecursivo/publicaciones_digitales/Est/Lib1251/Libro.pdf. Fecha de consulta: 10 de julio de 2016.

Instituto Nacional de Estadística e Informática (2015b). Perú: Síntesis Estadística 2015. Lima: INEI. Recuperado de https://www.inei.gob.pe/media/ MenuRecursivo/publicaciones_digitales/Est/Lib1292/libro.pdf. Fecha de consulta: 6 de agosto de 2016.

Instituto Peruano de Economía (2009). El Reto de la Infraestructura al 2018. La brecha de inversión en infraestructura al 2008. Lima: IPE. Recuperado de: http://www.ipe.org.pe/documentos/el-reto-de-la-infraestructura-al-2018

INTERNATIONAL RENEWABLE ENERgy AgENCY (2014). Evaluación del Estado de preparación de las energías renovables 2014. Perú. Abu Dhabi: IRENA.

International Renewable Energy Agency (2015). Energías Renovables en América Latina en 2015: Sumario de Políticas. Abu Dhabi: IRENA.

IUS ET VERITAS (2009). "A tajo abierto: "explorando" la intervención estatal en la actividad minera». Trabajo del Grupo de investigación de Ius et Veritas. Ius La Revista, $\mathrm{N}^{\circ} 35$, 486-521. Lima: PUCP.

Lamadrid Ubillús, Alejandro (2011). Derecho Ambiental contemporáneo. Crisis y desafíos. Lima: Ediciones Legales.

Ministerio del Ambiente (2011). Compendio de la legislación ambiental peruana. Volumen I. Lima: MINAM/ Dirección General de Políticas, Normas e Instrumentos de Gestión Ambiental.

Ministerio DE Cultura (2016). Caral, patrimonio mundial. Lima: MC. Recuperado de http://www.zonacaral.gob.pe/gestion-y-proteccion-de-sitios-arqueologicos/ patrimonio-mundial. Fecha de consulta: 10 de julio de 2016. 
Ministerio de ECONOMÍA y FinANZAs (2012). Elaboración de la Nueva Matriz Energética Sostenible y Evaluación Ambiental Estratégica, como Instrumentos de Planificación. Lima: MEF-UCPS.

Ministerio de EnERgía y Minas (2008). Atlas Eólico del Perú. Lima: MEM/DGER/DFC

Ministerio de Energía y Minas (2014). Plan Energético Nacional 2014-2025. Documento de trabajo. Resumen Ejecutivo. Lima: MEM.

Ministerio DE ENERGía y MinAs (2016). Plan Nacional de Electrificación Rural (PNER) Período 2016-2024. Resolución Ministerial № 579-2015-MEM/DM. Ministerio de Energía y Minas. Lima, MEM, 2016. Recuperado de http://dger. minem.gob.pe/ArchivosDger/PNER_2015-2024/F4-PNER-Dptos-2015-24. pdf. Fecha de consulta: 8 de agosto de 2016.

OrRego Moya, Roxana (2011). Estado del Arte y Novedades de la Bioenergía en el Perú. Lima: FAO Oficina Regional para América Latina y El Caribe - RLC.

Osinergmin (2014). Gas natural en el Perú. A diez años del proyecto Camisea. Lima: OSINERGMIN.

OSINERGMIN (2016). Cuarta subasta RER para suministro de energía al sistema eléctrico interconectado (SEIN). Lima: OSINERGMIN. Recuperado de http://www2. osinerg.gob.pe/EnergiasRenovables/contenido/4taSubastaRER.html. Fecha de consulta: 6 de agosto de 2016.

Programa de las Naciones Unidas PaRa El DesarRollo (2016). Informe regional sobre Desarrollo Humano para América Latina yel Caribe. Progreso multidimensional: bienestar más allá del ingreso. New York: PNUD.

Schmidt-Pramov Fabian/ Cooperación Alemana al Desarrollo GIZ/ (2016). Perú. Mejora de la gestión y el financiamiento del sistema de áreas naturales protegidas. Lima: GIZ. Recuperado de https://www.giz.de/en/worldwide/26019.html Fecha de consulta: 6 de agosto de 2016.

Seminario, Bruno (2008). El Costo Económico del Cambio Climático en la Comunidad Andina. Lima: Universidad del Pacífico.

SENAMHI (2003). Atlas de Energía Solar del Perú. Lima: SENAMHI-MEM.

StERn, Nicholas (2006). The Economics of Climate Change. Nueva York: Cambrigde University Press.

Stiglitz, Joseph E. (2007). Globalização: como dar certo. São Paulo: Companhia das Letras.

VALDEZ MuÑoz, WALTER (2013). «Marco institucional para la gestión ambiental en el Perú». Derecho PUCP. Revista de la Facultad de Derecho, № 70, 45-62. Lima: PUCP. Recuperado de http://revistas.pucp.edu.pe/index.php/derechopucp/ article/view/6743

Vargas, Paola (2009). El Cambio Climático y Sus Efectos en el Perú. Documento de trabajo. Lima: Banco Central de Reserva del Perú. Recuperado de http:// www.riesgoycambioclimatico.org/biblioteca/archivos/DC1136.pdf 
VelÁsquez, J. (2007). Mapa Eólico preliminar del Perú. Lima: ADINELSA.

Verna Coronado, Vito (2013). «Tres áreas en la evolución de la regulación del impacto ambiental». Derecho PUCP. Revista de la Facultad de Derecho, № 70, 63-81. Lima: PUCP. Recuperado de http://revistas.pucp.edu.pe/index.php/ derechopucp/article/view/6744

Zavala, Abel, Enrique Guadalupe y Norma Carrillo (2007). «El gas de Camisea: geología, economía y usos». Revista del Instituto de Investigaciones FIGMMG-UNMSM, vol. 10, № 19, 113-119. Lima: UNMSM. Recuperado de http://revistasinvestigacion.unmsm.edu.pe/index.php/iigeo/article/ view/2766/2396 